\title{
Precipitation seasonality and variability over the Tibetan plateau as resolved by the High Asia reanalysis
}

Article

Published Version

Maussion, F., Scherer, D., Mölg, T., Collier, E., Curio, J. and Finkelnburg, R. (2014) Precipitation seasonality and variability over the Tibetan plateau as resolved by the High Asia reanalysis. Journal of Climate, 27 (5). pp. 1910-1927. ISSN 1520-0442 doi: https://doi.org/10.1175/JCLI-D-13-00282.1 Available at https://centaur.reading.ac.uk/69080/

It is advisable to refer to the publisher's version if you intend to cite from the work. See Guidance on citing.

To link to this article DOI: http://dx.doi.org/10.1175/JCLI-D-13-00282.1

Publisher: American Meteorological Society

All outputs in CentAUR are protected by Intellectual Property Rights law, including copyright law. Copyright and IPR is retained by the creators or other copyright holders. Terms and conditions for use of this material are defined in the End User Agreement.

www.reading.ac.uk/centaur 
Central Archive at the University of Reading

Reading's research outputs online 


\title{
${ }^{\partial}$ Precipitation Seasonality and Variability over the Tibetan Plateau as Resolved by the High Asia Reanalysis*
}

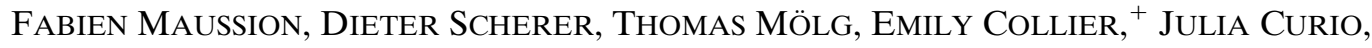 \\ AND ROMAN FINKELNBURG \\ Chair of Climatology, Technische Universität Berlin, Berlin, Germany
}

(Manuscript received 14 May 2013, in final form 4 October 2013)

\begin{abstract}
Because of the scarcity of meteorological observations, the precipitation climate on the Tibetan Plateau and surrounding regions (TP) has been insufficiently documented so far. In this study, the characteristics and basic features of precipitation on the TP during an 11-yr period (2001-11) are described on monthly-to-annual time scales. For this purpose, a new high-resolution atmospheric dataset is analyzed, the High Asia Reanalysis (HAR), generated by dynamical downscaling of global analysis data using the Weather Research and Forecasting (WRF) model. The HAR precipitation data at 30- and 10-km resolutions are compared with both rain gauge observations and satellite-based precipitation estimates from the Tropical Rainfall Measurement Mission (TRMM). It is found that the HAR reproduces previously reported spatial patterns and seasonality of precipitation and that the highresolution data add value regarding snowfall retrieval, precipitation frequency, and orographic precipitation. It is demonstrated that this process-based approach, despite some unavoidable shortcomings, can improve the understanding of the processes that lead to precipitation on the TP. Analysis focuses on precipitation amounts, type, seasonality, and interannual variability. Special attention is given to the links between the observed patterns and regional atmospheric circulation. As an example of an application of the HAR, a new classification of glaciers on the TP according to their accumulation regimes is proposed, which illustrates the strong spatial variability of precipitation seasonality. Finally, directions for future research are identified based on the HAR, which has the potential to be a useful dataset for climate, glaciological, and hydrological impact studies.
\end{abstract}

\section{Introduction}

The Tibetan Plateau and adjacent mountain ranges (TP)—Himalayas, Karakoram, Pamir, Kunlun, and Qilian Shan (cf. Fig. 1) - play a crucial role for downstream hydrology and water availability in Asia (Immerzeel et al. 2010). Rainfall, snowmelt, and, to a lesser extent, glaciers dominate the hydrological budget of the TP (Bookhagen and Burbank 2010), but the relative importance of these

ə Denotes Open Access content.

\footnotetext{
* Supplemental information related to this paper is available at the Journals Online website: http://dx.doi.org/10.1175/JCLID-13-00282.s1.

${ }^{+}$Additional affiliation: Department of Earth and Atmospheric Sciences, University of Alberta, Edmonton, Alberta, Canada.
}

Corresponding author address: Fabien Maussion, Technische Universität Berlin, Chair of Climatology, Rothenburgstr. 12, 12165 Berlin, Germany.

E-mail: fabien.maussion@tu-berlin.de factors varies largely between regions and watersheds (Kaser et al. 2010). Most glaciers in the Himalayas (Bolch et al. 2012) or on the Tibetan Plateau (Yao et al. 2012) are retreating, but they show contrasting patterns of shrinkage (Kääb et al. 2012). Local factors (e.g., exposition, topography, and debris coverage) partly account for these differences, but spatial and temporal heterogeneity of climate and climate change (Palazzi et al. 2013) play a role that has yet to be quantified, especially in the regions where in situ measurements are nonexistent.

The TP climate is under the combined and competitive influences of the East Asian and South Asian monsoons (Webster et al. 1998) and of the westerlies (Schiemann et al. 2009). The role of the TP as a controlling factor for the Asian monsoon system and for atmospheric circulation at hemispheric scale has been studied for a long time (Hahn and Manabe 1975) and continues to be a key research topic (e.g., Molnar et al. 2010; Wu et al. 2012). While the mechanical and thermal effects of the highly elevated TP on global circulation patterns has received much attention, the strength and nature of the couplings between the various monsoon 

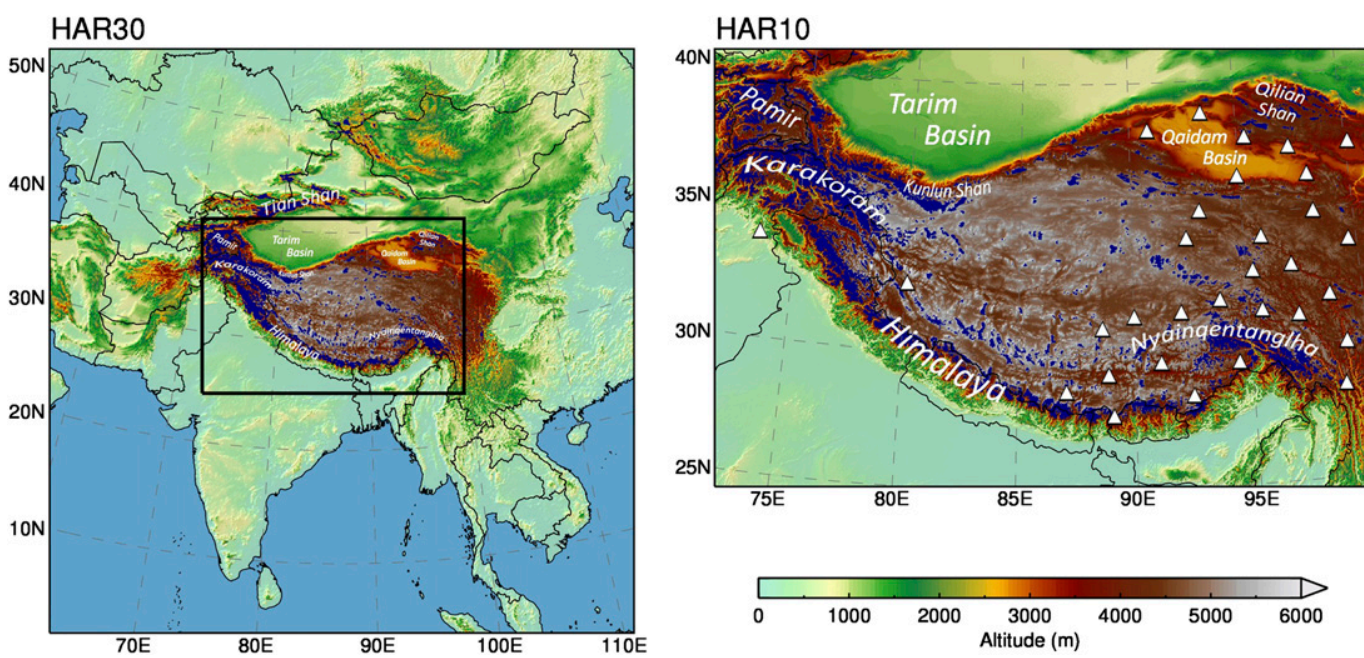

FIG. 1. Maps of the WRF model domains HAR30 (south-central Asia domain, 30-km resolution; $200 \times 200$ grid points) and HAR10 (High Asia domain, 10-km resolution; $270 \times 180$ grid points). Glacier outlines from the Randolph glacier inventory are drawn in blue, and the positions of the NCDC stations used for the validation are indicated by white triangles. Geographical locations mentioned in the text are indicated.

systems and the westerlies and especially their effects on TP precipitation variability remain less studied so far.

A substantial part of precipitation on the TP falls as snow. Spring TP snow cover has been proven to be a significant predictor for southwest Asian monsoon variability (Immerzeel and Bierkens 2010). The variability of snowfall frequency and intensity during spring/ summer and related surface albedo conditions on glaciers also have a considerable impact on glacier mass balance. The timing and amount of snowfall in the early ablation (mass loss) season is a key process for the surface energy balance of glaciers and anomalous events (either dry or wet) initiate effects that can persist during the entire ablation season (e.g., Mölg et al. 2012; Yang et al. 2011, 2013). Glaciers on the TP are diverse in type regarding accumulation and ablation patterns, which are largely tied to precipitation amount and seasonality (Fujita 2008; Shi and Liu 2000).

The major reason for our lack of knowledge about the TP climate is the paucity of meteorological data. Permanent weather stations are scarce and confined to lower altitudes (Qin et al. 2009) and therefore are not representative of the high mountain climates. Global reanalysis datasets have coarse resolution that limits their representation of the mountainous topography. Of all climatological elements affected by topography, precipitation is probably the most complex and the most poorly represented by coarse-resolution grids (e.g., You et al. 2012; Bohner 2006).

Regional numerical weather prediction (NWP) models can be used to simulate precipitation fields and other meteorological variables at a high-spatiotemporal resolution.
Longer time spans of years to decades can be simulated by NWP models by successive reinitialized model runs of shorter periods forced by large-scale observational datasets (e.g., Lo et al. 2008). In this study, we present a dataset generated using this method, that provides a tool to study atmosphere-related processes on the TP [the High Asia Reanalysis (HAR), described in section 2]. The HAR spans a period of more than $11 \mathrm{yr}$ (October 2000-December 2011) and comprises two datasets with different spatial coverage and objectives: a domain of $30-\mathrm{km}$ resolution including most parts of south and central Asia and a nested domain of $10-\mathrm{km}$ resolution covering the TP and most parts of High Asia (Fig. 1). For simplicity, we use the acronym TP when referring to the Tibetan Plateau and surrounding mountain ranges as comprised in the 10-km-resolution High Asia domain.

The purpose of this study is twofold:

(i) describe the characteristics of precipitation (amount, type, seasonality, and variability) on the TP at monthly to annual time scales and obtain a more spatially detailed pattern than is possible from the few available observations (Fig. 1), as far as allowed by the accuracy and the resolution of the HAR and

(ii) provide some insights into the factors that lead to precipitation on the TP and propose perspectives for future research based on the HAR.

Producing accurate precipitation data using an atmospheric model is not trivial. Maussion et al. (2011, hereafter MA11) conducted a sensitivity analysis for a 1-month period during which strong rainfall and snowfall occurred on the TP and evaluated the model precipitation output 
with (i) eight different physical parameterization schemes and (ii) several nesting and reinitialization configurations. No physical parameterization scheme outperformed the others for all the tests, but much effort went into choosing the model setup that performs best to produce the dataset presented in this study. In the first part of this paper, we assess the HAR precipitation output for the 11-yr period and evaluate its accuracy and potential errors. This evaluation is carried out by all available means; that is, by comparing the simulated precipitation with available surface and satellite observations but also by analyzing precipitation patterns and seasonality in the broader context of our current knowledge about precipitation in complex terrain and on the TP. The temporal resolution and extent of the HAR allows the analysis of processes from hourly to interannual time scales. In this study, we will not analyze diurnal cycles of precipitation or single stochastic weather events, although such aspects could also be addressed with the HAR dataset (see MA11).

In the following section, we describe the methods used to produce the HAR. The datasets used for the validation of the precipitation data are described in section 3 . In section 4, we present and discuss the results. Section 5 shows an application example and provides a new map of glacier accumulation regimes based on precipitation seasonality. In section 6 , we draw the conclusions of our study.

\section{The High Asia Reanalysis dataset}

To obtain gridded meteorological data at high-spatial and high-temporal resolutions, one general approach is to dynamically downscale a gridded global dataset that has been produced by data assimilation of a multitude of quality-controlled observations. Through data assimilation on the global scale, the resulting analysis or reanalysis dataset represents a physically consistent "best guess" of the state of the atmosphere at each time (usually at 6-h intervals). One of the basic requirements of our approach is that the downscaled data should represent as closely as possible the information that suitable observations would have delivered. This implies that the conditions at Earth's surface influencing atmospheric processes, particularly in the boundary layer, need to be described in sufficient spatial detail.

Lo et al. (2008) analyzed different dynamical downscaling methods and showed that consecutive reinitialized runs outperformed continuous long-term integrations with a single initialization, in particular when the reinitialization frequency was weekly instead of monthly. Other studies (e.g., von Storch et al. 2000) have successfully applied spectral nudging to continuous long-term integrations for dynamical downscaling, a technique that prevents the model from drifting away from the driving large-scale states while concurrently allowing the development of mesoscale processes. The major drawback of the latter method for our purposes is that no reinitialization takes place during which assimilated observations could possibly correct drifts in the land surface model or near-surface atmospheric variables.

MA11 tested different options for dynamical downscaling using reinitialization. Using almost the same domain as in this study, they showed for a test case that reinitialization sequences of daily runs outperformed weekly simulations. Based on these findings, we decided to follow a daily reinitialization strategy, which additionally prevents the land surface model from drifting away from the states provided by the analysis data. Several studies made use of this technique for regions of comparable environment (complex terrain and scarce observations): for example, Iceland (Bromwich et al. 2005), Greenland (Box et al. 2006), and the Arctic (Wilson et al. 2011).

The NWP model used to generate the HAR is the Advanced Research Weather Research and Forecasting model (WRF-ARW; Skamarock and Klemp 2008). The dataset consists of consecutive reinitialized model runs of 36-h time integration. Each run starts at 1200 UTC. The first $12 \mathrm{~h}$ from each run are discarded as spinup while the remaining $24 \mathrm{~h}$ of model output provide 1 day of the 11-yr-long time series. The model configuration used for the HAR is summarized in Table 1. The model is forced with the GFS operational model global tropospheric analyses [final analysis (FNL); dataset ds083.2], which are available every $6 \mathrm{~h}$ and have a spatial resolution of $1^{\circ}$. FNL data rely on numerous data sources, such as remote sensing data from Earth observing satellites assimilated together with surface and upper air reports from global observation networks. The data include pressure, geopotential height, temperature, dewpoint temperature, and wind direction and speed (National Centers for Environmental Prediction 2014). In the development phase of the HAR, the Interim European Centre for Medium-Range Weather Forecasts (ECMWF) Re-Analysis (ERA-Interim) dataset (Dee et al. 2011) was evaluated as a possible forcing dataset. We found that the accuracy of the HAR precipitation was improved when driven by FNL (Figs. S1-S3; see supplementary material). Moreover, initialization issues with ERA-Interim related to the treatment of snow cover in heavily glaciated grid cells ${ }^{1}$ (Collier et al. 2013; Figs. S4-S6) and a summer cold bias on the TP further supported the choice of FNL.

\footnotetext{
${ }^{1}$ In ERA-Interim, snow depth is arbitrarily initialized at $10 \mathrm{~m}$ for grid cells with greater than $50 \%$ glacier coverage.
} 
TABLE 1. HAR model strategy.

\begin{tabular}{|c|c|}
\hline \multicolumn{2}{|l|}{ Map and grids } \\
\hline Map projection & Lambert conformal \\
\hline Center point of domain & $30.0^{\circ} \mathrm{N}, 87.0^{\circ} \mathrm{E}$ \\
\hline Number of vertical layers & 28 \\
\hline Horizontal grid spacing & $30 \mathrm{~km}$ and $10 \mathrm{~km}$ \\
\hline Unstaggered grid points & $200 \times 200$ and $270 \times 180$ \\
\hline Static geographical fields & $\begin{array}{l}\text { U.S. Geological Survey (USGS) } \\
\text { dataset at } 10^{\prime} \text { and } 5^{\prime} \text { resolution, } \\
\text { glacier outlines from the RGI V1 }\end{array}$ \\
\hline \multicolumn{2}{|l|}{ Timing } \\
\hline Simulation period & October 2000-September 2011 \\
\hline Time step & $120 \mathrm{~s}$ and $40 \mathrm{~s}$ \\
\hline \multicolumn{2}{|l|}{ Nesting strategy } \\
\hline Nesting & $\begin{array}{l}\text { Two-way nesting in cascade } \\
\text { simulations }\end{array}$ \\
\hline \multicolumn{2}{|l|}{ Forcing strategy } \\
\hline Boundary conditions & $\begin{array}{l}\text { National Centers for Environmental } \\
\text { Prediction (NCEP) FNL from } \\
\text { Global Forecast System (GFS) } \\
\text { operational model global tropo- } \\
\text { spheric analyses }\left(1^{\circ}, 6 \text { hourly) }\right.\end{array}$ \\
\hline Sea surface temperature & $\begin{array}{l}\text { NCEP Marine Modeling and } \\
\text { Analysis Branch (MMAB) } \\
\text { real-time global SST (RTG_SST) } \\
\text { analysis }\left(0.5^{\circ}, \text { daily) }\right.\end{array}$ \\
\hline Lake surface temperature & $\begin{array}{l}\text { WRF model inland water module } \\
\text { (avg_tsfc) }\end{array}$ \\
\hline Initialization & Daily \\
\hline Runs starting time & Daily, 1200 UTC \\
\hline Runs duration & $36 \mathrm{~h}$ \\
\hline Spinup & $12 \mathrm{~h}$ \\
\hline \multicolumn{2}{|c|}{ Physical parameterization schemes } \\
\hline Shortwave radiation & Dudhia scheme \\
\hline Longwave radiation & $\begin{array}{l}\text { Rapid Radiative Transfer Model } \\
\text { (RRTM) }\end{array}$ \\
\hline Cumulus parameterization & New Grell-Devenyi 3 sheme \\
\hline Microphysics & Modified Thompson scheme \\
\hline Land surface model & Noah land surface model (LSM) \\
\hline PBL & $\begin{array}{l}\text { Mellor-Yamada-Janjić turbulent } \\
\text { kinetic energy (TKE) }\end{array}$ \\
\hline
\end{tabular}

In this study, a few minor setup changes with respect to MA11 were made, including upgrading the WRF model to version 3.3.1 and using the recently introduced inland water surface temperature initialization module. Since we expect the HAR dataset to be used as input data for hydrological and glaciological modeling, an adequate representation of ice-covered ground is important. Thus, we updated the original ice mask in the geographical land cover data with the Randolph glacier inventory, version 1.0 (RGI V1; Arendt et al. 2012). Since these modifications have a limited impact on the model output at regional scale (Collier et al. 2013), they will not be discussed here. The two-way nested cascading approach defined in MA11 has been followed here too. First the 10-km-resolution domain is run within the $30-\mathrm{km}$ domain using the two-way nesting option, and then the 30-km-resolution domain is run alone to avoid inconsistencies due to the presence of the child domain. This allows us to consider the WRF model at $30 \mathrm{~km}$ (HAR30) and WRF model at $10 \mathrm{~km}$ (HAR10) as two different, complementary datasets.

Our approach using dynamical downscaling with shortterm integration and daily reinitialization can be called "regional reanalysis," following the ideas of, for example, Kanamitsu and Kanamaru (2007) or von Storch et al. (2000), who concluded that dynamical downscaling using spectral nudging may be seen as an indirect data assimilation technique. For the HAR we have not, however, performed data assimilation on the regional level, as is the case with "true" regional reanalyses like the North American Regional Reanalysis (NARR). Because of the scarcity of both surface observations and radio soundings as well as their inaccessibility, variational data assimilation is not possible for the TP. To our knowledge, such a comprehensive and process-based dataset is currently unique for the TP, and therefore the HAR is intended to fill a gap where other regional reanalyses are not available.

For the potential users of the dataset (atmospheric scientists, hydrologists, glaciologists, etc.), the WRF model output has been postprocessed for easy use. We provide separate data files per variable, per year, and per time aggregation (hourly, daily, monthly, and yearly), as well as vertically interpolated fields at standard pressure levels in addition to the model sigma levels. A webpage has been created for HAR users where the data can be downloaded (available at http://www.klima.tu-berlin.de/ HAR). The range of applications of this dataset is rich and unexplored. So far, the HAR has been used by Mölg et al. $(2012$, 2014), who employed the HAR as input for a glacier energy and mass balance model; by Kropáček et al. (2013), who quantified the relation of air temperature and wind speed to the icing periods of large lakes on the plateau; and by Dietze et al. (2014), who analyzed sediment transport processes at four sites on the plateau.

We used the daily, monthly and yearly products from HAR30 and HAR10 (version 1) for this study. We consider the time span of October 2000-September 2011 but for simplicity we use the term "decade" for these 11 hydrological years. For the seasonality analyses we use the classical quarters: December-February (DJF), MarchMay (MAM), June-August (JJA), and SeptemberNovember (SON). To avoid singularities we removed 10 and 5 grid points from the HAR 30 and HAR 10 domain boundaries, respectively. Unless specified otherwise, all figures and analysis are made using the original model grids. 


\section{Validation data and assessment methods}

\section{a. Weather stations}

The HAR precipitation data are compared with rain gauge precipitation records from the "Global Summary of the Day" provided by the National Climatic Data Center (NCDC). We conduct our evaluation for the TP region. Thus, the weather stations selected for this study must satisfy two criteria: they are located within the HAR10 domain and are located above $2000 \mathrm{~m}$ MSL. We built monthly aggregated time series of precipitation rates ( $\mathrm{mm}_{\text {day }}{ }^{-1}$; day is abbreviated by $\mathrm{d}$ in figures) based on daily values and discarded months where less than $90 \%$ of the records were available. To ensure a correct reconstruction of the seasonal cycle at each station, we discarded the stations that did not include at least three valid months of each calendar month during the decade. After this filtering, 31 stations are left, of which 26 provide a gap-free time series, four contain a 1-month gap, and one has 51 valid months. The weather stations are not homogeneously distributed over the study region (Fig. 1), since they lie in more densely populated regions in the southern and eastern parts of the TP. In fact, some climatic precipitation regimes are not represented by this station population. To compare gridded precipitation data with the rain gauges, the nearest grid point is taken without interpolation (other interpolation methods-bilinear and cubic-did not change the results significantly). We use standard skill scores statistics for the assessment: mean deviation (MD; or mean bias), mean absolute deviation (MAD), and Pearson correlation coefficient $r$. For the daily precipitation occurrence statistics we use the Heidke skill score (HSS; Wilks 1995), computed from a contingency table (MA11, their Table 2). The HSS can only evaluate the detection or nondetection of discrete events; therefore, the tested events are defined as follows: precipitation exceeds a threshold $T$. The HSS indicates the capability of a simulation to be better or worse than a random simulation and ranges from -1 to 1 ( 1 for a perfect simulation and 0 for a random guess).

\section{b. TRMM precipitation}

Because of the uneven spatial distribution of the stations, we also compare the HAR precipitation output to precipitation estimates from the Tropical Rainfall Measuring Mission (TRMM). The TRMM precipitation estimates are derived from a combination of remote sensing observations calibrated against a large number of rain gauges on a monthly basis. In this study, the 3B42 (daily) and 3B43 (monthly) version 7 products are used (Huffman et al. 2007). The TRMM dataset covers the regions between $50^{\circ} \mathrm{N}$ and $50^{\circ} \mathrm{S}$ with a spatial resolution of $0.25^{\circ}$. It has been previously used to study convective activity on the TP (Yaodong et al. 2008) and in northern India (Medina et al. 2010), to study the diurnal cycle of precipitation over the TP (Zhou et al. 2008), and to validate atmospheric modeling studies (Chow and Chan 2009; MA11). The resolution of the TRMM 3B43 product $(\sim 28 \mathrm{~km})$ allows a quantitative evaluation of HAR30 precipitation only.

As indicated by its name, TRMM was primarily designed for measuring tropical (i.e.: convective) rainfall. It has been shown that its accuracy on the TP is affected by sampling problems because of low grid resolution (Bookhagen and Strecker 2008; Yin et al. 2008). The authors of the latter study emphasize that TRMM performs poorly during winter, because of the presence of snow and ice over the TP (snow and ice on the ground scatter microwave energy in a similar fashion as ice crystals and raindrops in the atmosphere). Therefore, TRMM estimates in winter and more generally over the TP region should be analyzed with care.

Additionally, we used the 1998-2009 rainfall climatologies from Bookhagen and Burbank (2010). This dataset is processed from the TRMM 2B31 product and is a rainfall estimate at higher resolution than the TRMM 3B43 product $(\sim 5 \mathrm{~km})$. Only the mean decadal climatologies are freely available, and they are computed for a slightly different period than the decade we consider. Therefore, we use the TRMM 2B31 dataset to qualitatively compare orographic precipitation with the HAR10 precipitation product.

\section{Results and discussion}

\section{a. Seasonal climatologies at the synoptic scale}

An overview of DJF and JJA climatologies derived from HAR30 is provided in Fig. 2. In DJF (left panel), a geopotential height $(\mathrm{GPH})$ gradient produces strong westerly winds (Figs. 2c,e) over much of the domain (the GPH maximum, hidden by the color scale, is located at $\left.\sim 13^{\circ} \mathrm{N}\right)$. The winter monsoonal land to sea breeze (e.g., Qian and Lee 2000) characterizes the surface wind regime in the tropics (Arabian Sea, Bay of Bengal, and South China Sea; Fig. 2a). On the TP the westerlies dominate while in the north, surface winds are heterogeneous. The DJF season is mostly dry (Fig. 2a): precipitation occurs over land 1) in central Asia and western TP as a result of the orographic uplift of the westerly flow, 2) at coastal areas under moist seabreeze flow (e.g., Vietnam, Malaysia, Sri Lanka), and 3) in southern China.

In JJA, the core Asian summer monsoons (ASM) season, the circulation patterns change dramatically. 
(a)

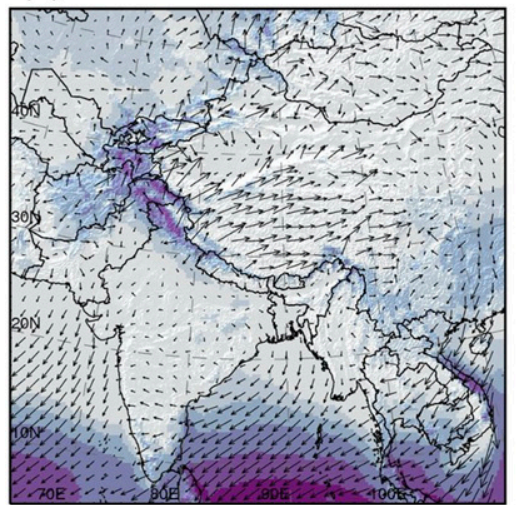

(c)

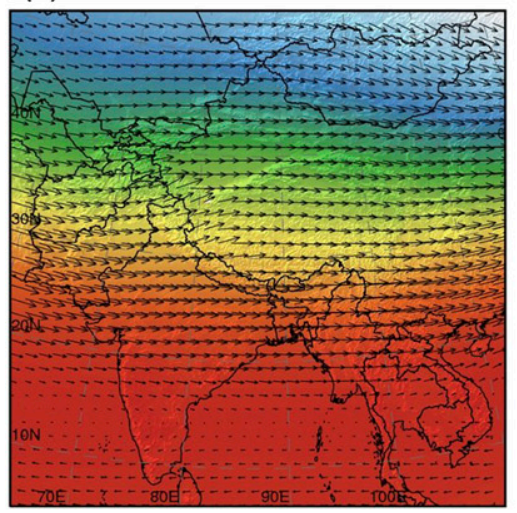

(e)

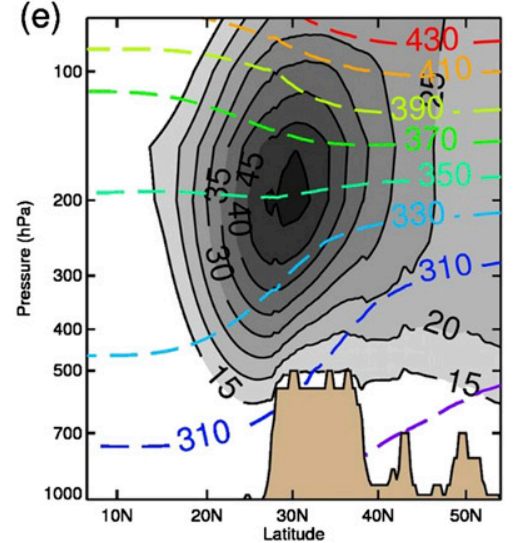

(b)

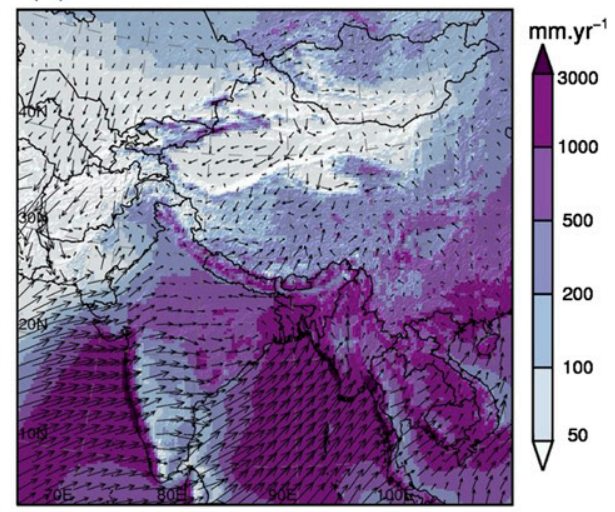

(d)

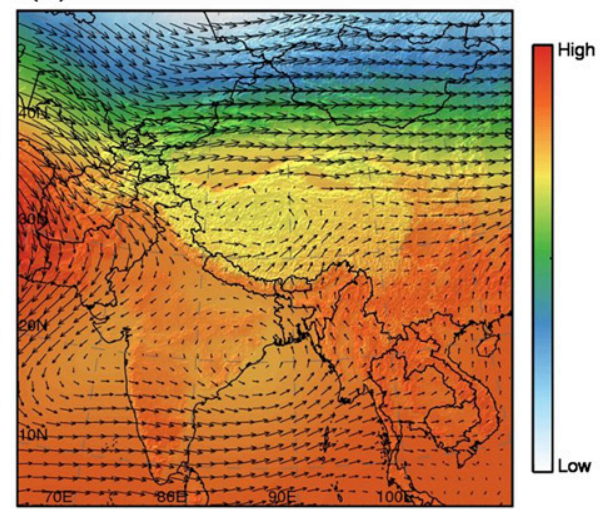

(f)

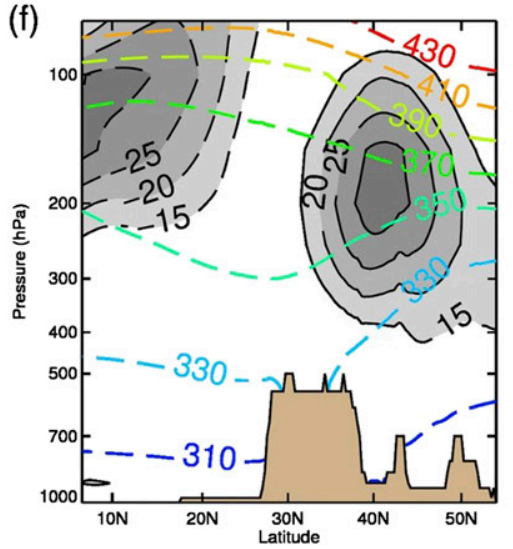

FIG. 2. Decadal (2001-11) seasonal means in the HAR30 dataset for (left) DJF and (right) JJA. (a),(b) Total precipitation and 10-m wind vectors (every fifth grid point). (c),(d) Geopotential height and horizontal wind vectors at the $500-\mathrm{hPa}$ level. Note that the color scale represents a different range for winter (low: $5.24 \mathrm{~km}$; high: $5.89 \mathrm{~km}$ ) and summer (low: $5.67 \mathrm{~km}$; high: $5.90 \mathrm{~km})$. (e),(f) Horizontal wind speed $\left(\mathrm{m} \mathrm{s}^{-1}\right.$; gray shades) and potential temperature (K; dashed color contours) along a latitude-pressure transect at $90^{\circ} \mathrm{E}$. Dashed gray contours represent negative zonal wind.

The reversal of surface winds over oceans and coasts is characteristic of the monsoonal climate (Fig. 2b). The westerly flow is weaker and the main jet axis is shifted to the north $\left(40^{\circ} \mathrm{N}\right.$; Fig. $\left.2 \mathrm{f}\right)$ as a result of the summer hemisphere heating. Simultaneously, the tropical easterly jet forms in the upper troposphere. The warmest air in the free atmosphere is now located south of the TP as evident from the potential temperature field, as a result of both surface and convective heating. Two midtroposphere low pressure systems characterize the mean 

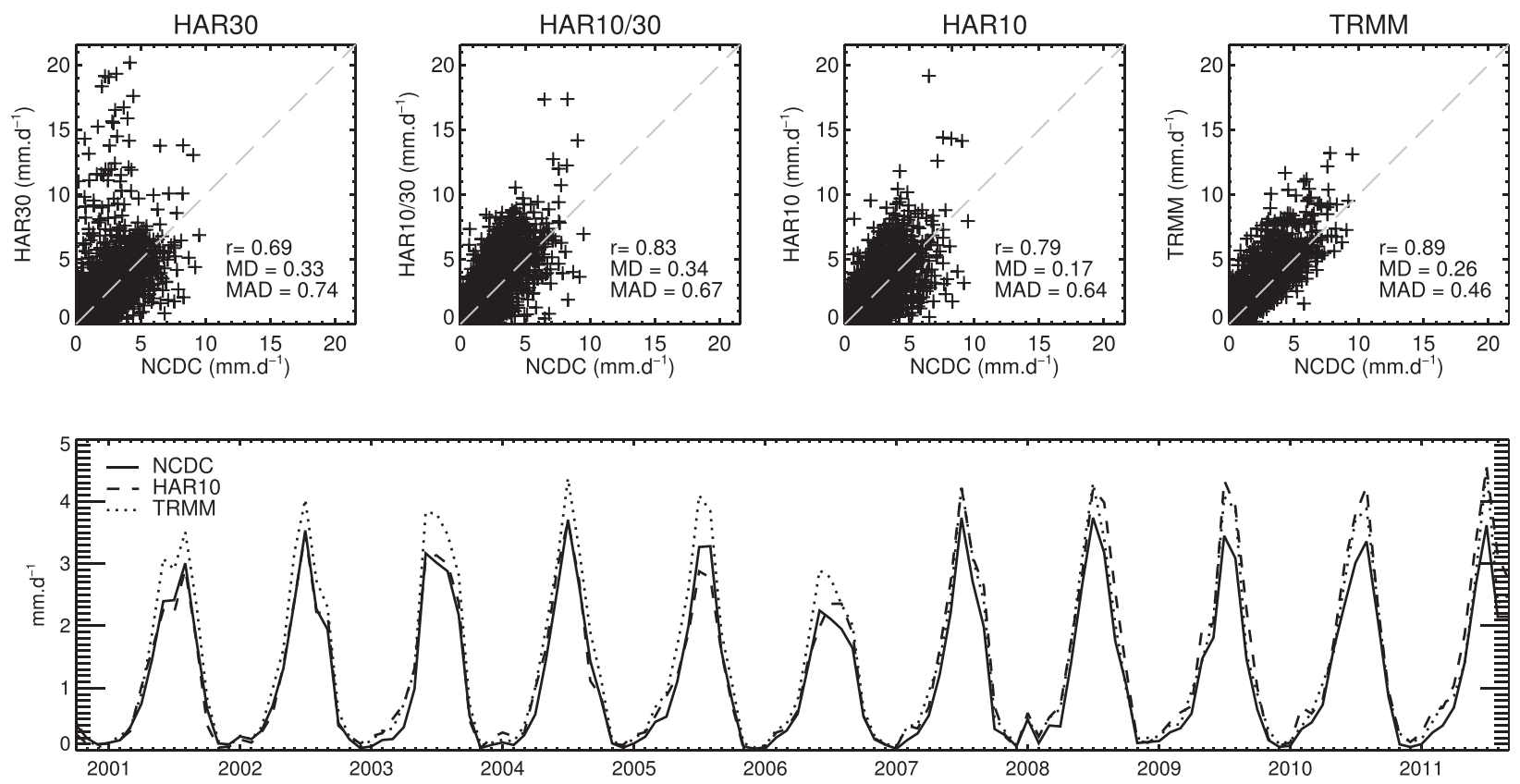

FIG. 3. Comparison of monthly precipitation rates $\left(\mathrm{mm} \mathrm{day}^{-1}\right.$; 2001-11) with NCDC stations observations (31 stations; 4007 valid months). (top) Scatterplots of HAR30, HAR10/30, HAR10, and TRMM 3B43 and statistical scores $r$, MD (mm day ${ }^{-1}$ ), and MAD $\left(\mathrm{mm} \mathrm{day}^{-1}\right)$. HAR10/30 is constructed by spatially averaging HAR10 on the HAR30 grid. (bottom) Monthly precipitation time series $\left(\mathrm{mm}\right.$ day $\left.^{-1}\right)$ averaged for all stations.

atmospheric circulation patterns at $500 \mathrm{hPa}$ (Fig. 2d; Wang 2006): the monsoonal depression over India (which extends from the surface up to $\sim 400 \mathrm{hPa}$ ) and the thermal low over the TP (confined to the TP boundary layer). Surface winds over the TP and partly over India follow the 500-hPa flow, with the exception of the Arabian Sea where surface winds are flowing in the opposite direction (they follow the Somali jet at $\sim 850 \mathrm{hPa}$; not shown). The combined blocking effects of topography and of the Tibetan low seem to divide the 500-hPa westerly flow reaching the TP in a south and north stream. As a result of the ASM circulation, precipitation is observed at the Indian southwest coast, in Bangladesh, in the Indochinese peninsula, and in southeast China (Fig. 2b). The blocking effect of the Himalayas on the low-level atmospheric flow is clearly visible, as well as the orographically induced precipitation spells at the mountain ridges. The Pamir and Karakoram mountain ranges are mostly dry, but the Tien Shan is wetter than in DJF.

\section{b. Comparison with observations}

\section{1) MONTHLY PRECIPITATION}

We compare HAR and TRMM monthly precipitation with station observations in Fig. 3. The top panel shows the scatterplots and skill statistics for all stations and months. The results indicate an improvement between HAR30 and HAR10, as the former tends to overestimate precipitation and shows larger scatter. This confirms the findings of MA11 and other studies (e.g., Heikkila et al. 2011) that demonstrated the positive effect of higher resolution in complex terrain on simulated precipitation. The added value of higher resolution is also evident when spatially averaging the HAR10 dataset on the HAR30 grid (HAR10/30). The HAR10/30 still shows an improvement to HAR30 and has even slightly better correlation values than HAR10, while the other HAR10 scores remain better. The TRMM 3B43 product better explains the variance at the stations (higher correlation and lower MAD) but has a larger positive bias (MD).

Precipitation seasonality and interannual variability is well reproduced by the HAR (Fig. 3, bottom panel). Anomalous events on the TP, such as the driest year 2006 or the wet winter of 2008, are well represented. For the averaged time series, HAR10 is closer to observations than the TRMM 3B43 product (MD of 0.089 and $0.26 \mathrm{~mm} \mathrm{day}^{-1}$ and MAD of 0.23 and $0.26 \mathrm{~mm} \mathrm{day}^{-1}$, respectively). However, the HAR diverges from the station data after 2007 in the summer months. The reasons for the disagreement are unclear, but the shift could be related to changes in the FNL assimilation system that occurred in 2007 (K. Manning 2013, personal communication). We compared HAR30 with the TRMM 3B43 product over the HAR30 domain and 
(a)

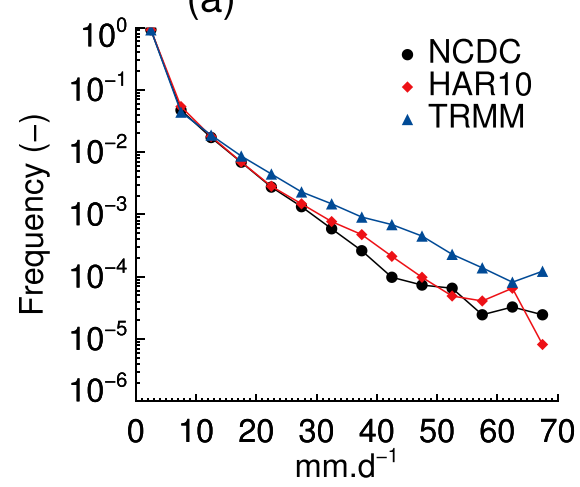

(b)

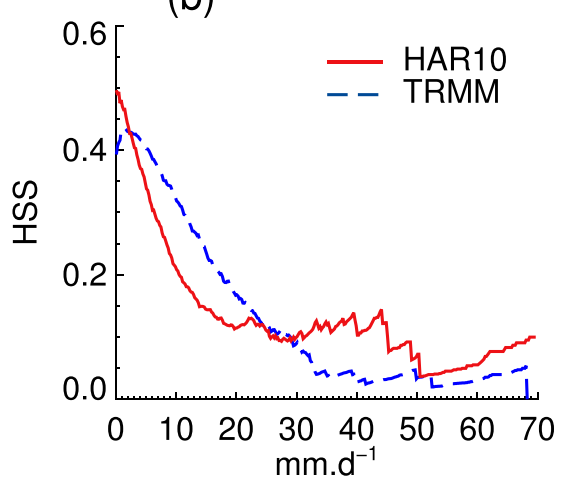

FIG. 4. (a) Histograms of daily precipitation amounts in the NCDC stations, HAR10, and TRMM data (note the logarithmic scale of the $y$ axis) and (b) HSS for daily precipitation.

found that the statistical metrics are regular and constant throughout the decade, and no singularities could be detected (see Fig. S7 in the supplemental material). Similarly, we reproduced the analysis presented in Fig. 3 for all stations available in HAR10 (not only on the TP, thus doubling the number of stations) and found that (i) the updated scores confirms the results of Fig. 3 and (ii) the period 2007-11 does not appear to be singular (Fig. S8). Therefore, we argue that this shift either is only occurring on the TP or is an artefact resulting from the small number of stations used for the validation.

In Fig. S9 of the supplemental material, we present further validation analysis, this time by considering the mean seasonal cycle at each station location. Most stations have a characteristic summer precipitation regime but there are variations in both shape and magnitude that are captured by the HAR. It is worth noting that both TRMM and HAR show inconsistent deviations (positive or negative) at stations located close to each other. Since both datasets are produced with a spatially consistent methodology, these discrepancies are probably related to spatial sampling problems.

\section{2) DAILY PRECIPITATION}

One of the key objectives of the regional reanalysis is to represent past weather and therefore to be able to trace precipitation events (see MA11 for a day-by-day analysis of a severe precipitation event on the TP). Figure 4a shows the histograms of daily mean precipitation at the station locations for HAR10 and TRMM 3B42. The three histograms are close to each other for lower precipitation amounts (about $92 \%$ of all days are found in the $0-5 \mathrm{~mm} \mathrm{day}^{-1}$ bin), but TRMM 3B42 overestimates the frequency of higher precipitation amounts (Zhou et al. 2008 also report that TRMM overestimates the frequency of precipitation in the diurnal variation).
The HAR10 histogram is close to the stations, even for the extreme events. The HSSs of TRMM 3B42 and HAR10 are displayed in Fig. 4b. The HAR is closer to the stations for small thresholds, a feature that could be a result of the known problems of TRMM in detecting small raindrops and other issues related to irregular satellite overpasses (Kidd and Levizzani 2011). The HSSs decay rapidly for larger thresholds and faster for HAR10 than for TRMM 3B42. For higher amounts HAR10 performs better again, in accordance with the histograms presented in Fig. 4a.

\section{c. Precipitation over the TP and orography}

Figure 5a shows the decadal mean of HAR10 annual precipitation over the TP. There are large regional contrasts, from less than $50 \mathrm{~mm} \mathrm{yr}^{-1}$ in the Tarim basin to more than $6000 \mathrm{~mm} \mathrm{yr}^{-1}$ (35 grid points) in the southeast Himalayan foothills. As shown in Fig. 2b, the moist flow originating in Bay of Bengal is blocked by the Himalayas and redirected northwest following the range, generating an east-west precipitation gradient. The uplift caused by the Himalayan range generates an orographically induced "precipitation barrier," leaving the regions north of the range with drier air masses and less precipitation. On the TP, there is a clear southeast-northwest gradient, which is often attributed to the fact that most of the moisture is transported from the southeast by the monsoonal flow (e.g., Feng and Zhou 2012).

For completeness, we plotted TRMM 3B43 mean precipitation for the same period (Fig. 5b) and the 19982008 rainfall decadal mean from TRMM 2B31 (Fig. 5c). Similar features are observable in all three datasets: for example, the location of precipitation maxima, the gradients, the precipitation belt along the Himalayas, and the dry Tarim and Qaidam basins. However, HAR10 and TRMM 2B31 are more in agreement for detailed patterns such as the dry spell in the lee side of the 
(a)

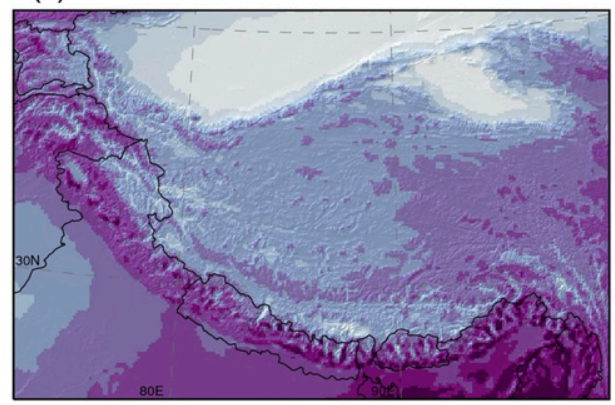

(c)

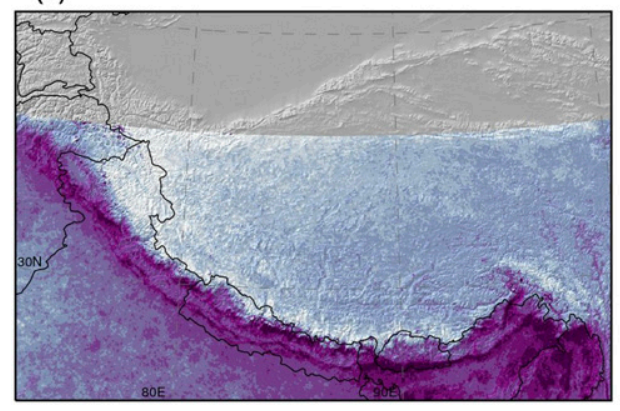

(b)

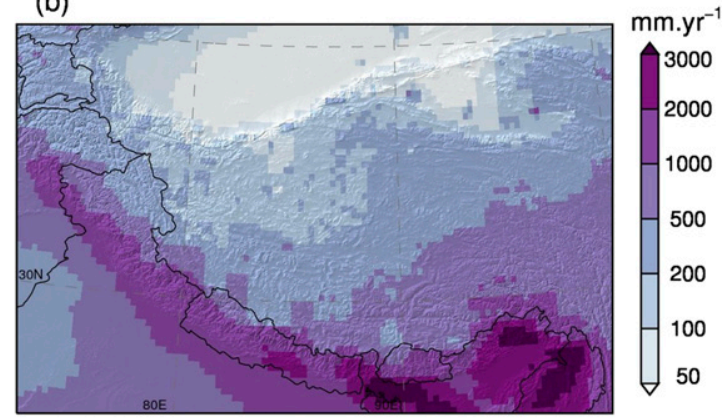

(d)

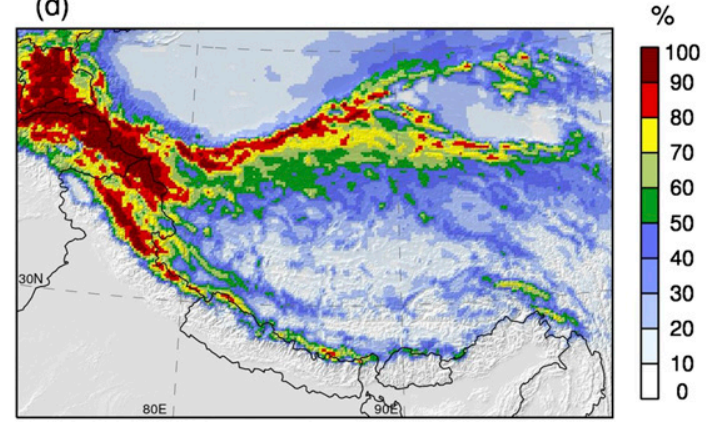

FIG. 5. Decadal means of annual precipitation for (a) HAR10 and (b) TRMM 3B43, (c) annual rainfall for TRMM 2B31, and (d) percentage of HAR10 precipitation falling as snow. Note that the decadal mean for TRMM 2B31 (1998-2008) covers a different period than HAR10 and TRMM 3B43 (2001-11).

Himalayas. The influence of orography is less pronounced in TRMM 3B43 on the TP, while it plays an obvious role in triggering precipitation in TRMM 2B31 and HAR10. The largest differences at regional scale between HAR10 and TRMM 3B43 are found in the Pamir and Karakoram regions and in northwestern Tibet. These regions experience mostly winter precipitation (Fig. 2a), with the majority falling as snow (Fig. 5d). The regions with large snowfall contribution to the total precipitation are the high mountains and the northwestern part of the TP, where temperatures are lower.

Interestingly, regions with larger discrepancies between TRMM and HAR10 correspond to areas with higher snowfall percentages. This is corroborated in Fig. 6, which shows the relative difference between TRMM 3B43 and HAR10 plotted against snowfall contribution at each grid point. There is a clear relationship between precipitation difference and snowfall, which is consistent with results of previous studies of possible TRMM detection errors of frozen precipitation (e.g., Yin et al. 2008). Although it is generally difficult to quantify the accuracy of the HAR snowfall data, there is support from studies in high mountains that the WRF model is able to reproduce observations (e.g., Mölg and Kaser 2011; Mölg and Scherer 2012). We repeat the analysis of Mölg and Scherer (2012) at one station location where snowfall information was available (Fig. S10 in the supplemental material) and found that the HAR captures well the phase of the precipitation compared with observations.

Bookhagen and Burbank (2010) suggested that two topographic classes can be defined along the Himalayas: either (i) the mean topography rises more or less steadily to an average elevation of $5 \mathrm{~km}$ (one-step topography) or (ii) it follows a two-step morphology in which the

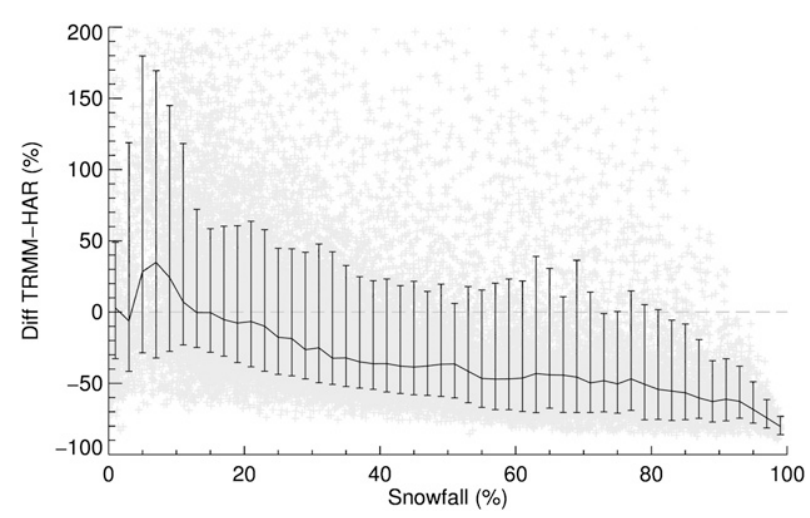

FIG. 6. Relative difference in annual precipitation between TRMM 3B43 and HAR10 with HAR10 as reference, as a function of annual snowfall fraction (\%) in the HAR data. Each gray point represents one data point, and the curve represents $2 \%$-wide binned median with $10 \%$ and $90 \%$ percentiles as error bars. 

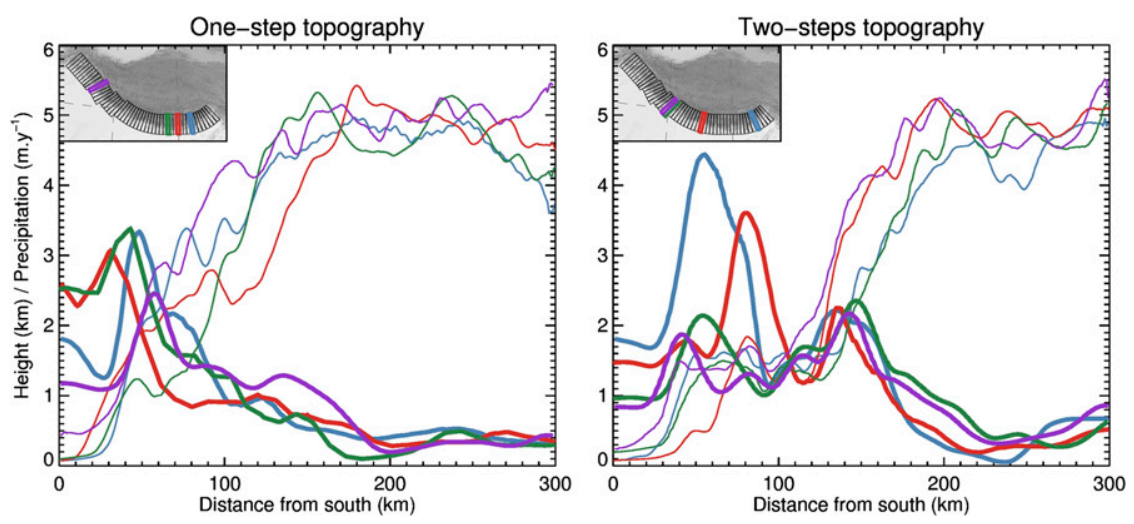

FIG. 7. Mean annual precipitation from HAR10 $\left(\mathrm{m} \mathrm{yr}^{-1}\right.$; thick lines) and 30-km Shuttle Radar Topography Mission (SRTM30) topography (km; thin lines) along four 50-km-wide and $300-\mathrm{km}$-long south-north swaths. The swaths locations are indicated in the inset maps [swaths from Bookhagen and Burbank (2010)].

outer step corresponds to the Lesser Himalayas and the inner step to the Higher (Greater) Himalayas. The authors showed that precipitation in TRMM 2B31 mimics these two classes of topographic profiles. Such patterns are expected and known from the underlying processes of mountain-airflow interactions (e.g., Colle 2008). To evaluate HAR10 precipitation in this context, we computed the mean transect precipitation along several profiles and show examples of the two classes in Fig. 7. The HAR precipitation profiles follow similar features as the profiles in Bookhagen and Burbank (2010, their Fig. 7) but seem to slightly underestimate precipitation maxima, perhaps because of the coarser resolution of the HAR. This analysis underlines the importance of topography and snowfall for precipitation patterns on the TP and the added value of high-resolution modeling in this region.

Altogether, these results give confidence in the accuracy of the HAR with respect to the requirements of this study and indicate that it is free of a systematic precipitation error. Previous studies reported that the WRF model overestimates precipitation in mountainous terrain (e.g., Caldwell et al. 2009), but we find no evidence for this. Area averaged over the whole HAR10 domain, the model produces $15 \%$ more precipitation than TRMM 3B43 (734 versus $636 \mathrm{~mm} \mathrm{yr}^{-1}$, respectively), which we assume to be partly related to problems of TRMM snowfall retrievals.

\section{d. Precipitation timing and seasonality on the TP}

Figure 8 shows the contribution of each season to annual precipitation during the last decade. The Karakoram and Pamir regions form one coherent unit, with most precipitation falling in DJF and MAM and almost no precipitation in JJA. Precipitation in MAM shows two bands (north and south of the TP), indicating that these two spells have different origins. Most precipitation in the domain falls in JJA, especially in India and central TP but also in the northeasterly Qilian Mountains. In SON the patterns are fairly uniform, representing $10 \%-20 \%$ of the annual precipitation.

We analyze the seasonal cycle of precipitation in Fig. 9, this time by showing the contribution of each month to the annual precipitation, together with mean horizontal wind vectors at the 500-hPa level. With a height of approximately $5700 \mathrm{~m}$, this level is a good indicator for the TP boundary layer flow. We start the description of the annual cycle in October, beginning of the hydrological year and end of the monsoon period. Low precipitation occurs in the southeast of the domain, and the winter precipitation season in the northwestern TP is starting. The seasonal cycle of precipitation in the northwest is tied to the location of the jet stream (Schiemann et al. 2008). Moisture is brought by southwesterly cyclones from the east of the Mediterranean and the Arabic Sea but under the stable winter conditions precipitation is mostly triggered by orography (e.g., Jiang 2003). From November to March, the 500-hPa zonal flow is constant and hardly perturbed by the mountains. The maximal winter precipitation intensity is reached in February. In March, the westerly jet starts to shift to the north, marking the beginning of the precipitation season in northern TP, which culminates in May-June. The first disturbances of the winter zonal flow occur in April, and the first indications for the formation of the Tibetan low appear in May. The center of this cyclonic system is not located in the south of the TP as one might expect because of stronger solar heating. Its location could be related to a combination of thermal and dynamical effects (Sugimoto and Ueno 2010). 


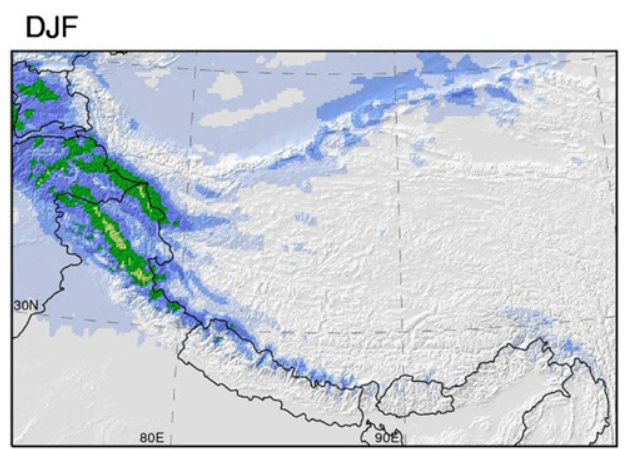

JJA

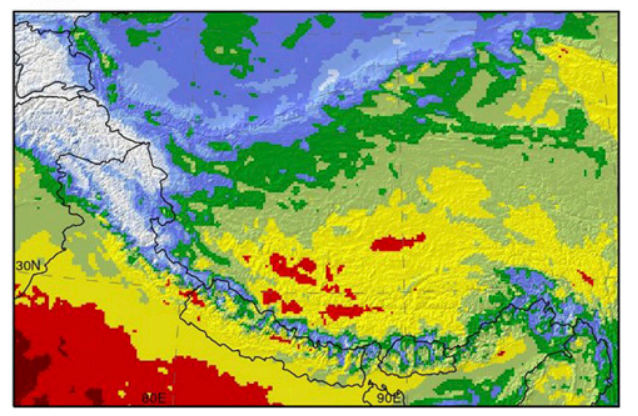

MAM

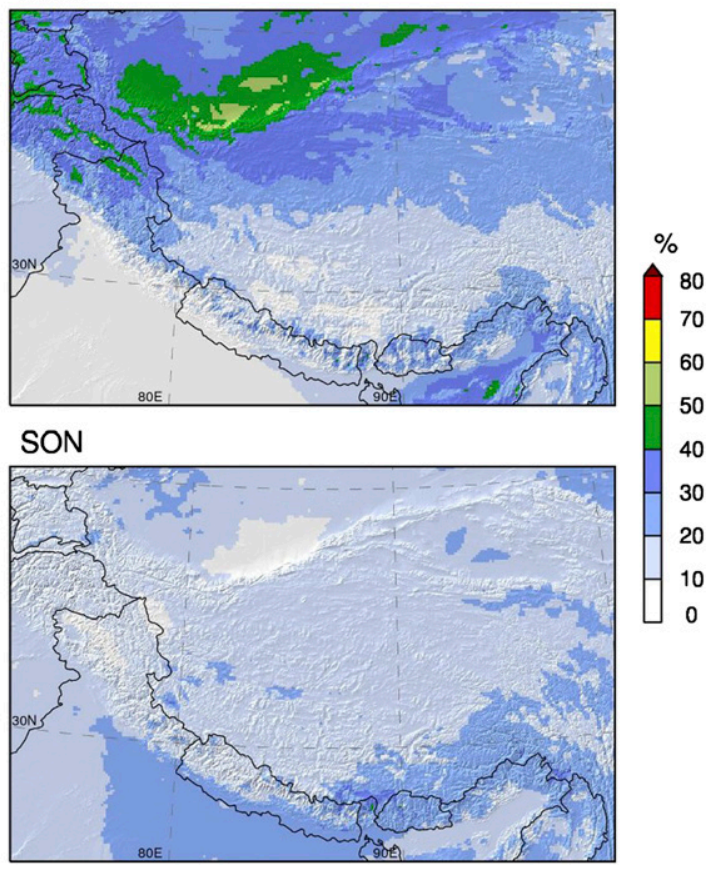

FIG. 8. Contribution (\%) of DJF, MAM, JJA, and SON to the HAR10 mean annual precipitation.

The cyclonic circulation on the plateau is established months before the monsoonal circulation, characterized by a reversal of the flow south of the Himalayas. The circulation patterns on the TP during the transition phase (May-June) suggest a combined influence of southerly and westerly flows on precipitation on the TP. The circulation conditions remain stable in July and August, and the wet spell on the TP originates from its southern and eastern parts. There is an abrupt transition between the dry Pamir-Karakoram region and the wetter Pakistan lowlands. Finally, in September the Tibetan low decays and the remainder of the summer precipitation is evenly distributed over the TP.

\section{e. Precipitation frequency and role of convective precipitation}

Figure 10a shows the average number of precipitation days $\left(>1 \mathrm{~mm} \mathrm{day}^{-1}\right)$ per hydrological year. The number of precipitation days is related to precipitation amounts (cf. Fig. 5a), but this relationship is neither constant nor linear, as shown in Fig. 10c. As indicator for the occurrence of strong precipitation events, we count the smallest number of precipitation days needed to reach $50 \%$ of the yearly precipitation amounts (on average) and we divide it by the number of precipitation days shown in Fig. 10a to obtain Fig. 10b. A location with constant and regular precipitation days will then have a value of $50 \%$, and a location with mostly light precipitation days but with a few strong precipitation events will have a lower value. We see in Fig. 10c that the number of days needed to reach $50 \%$ of the yearly precipitation is less dependent on the precipitation amount than precipitation frequency: it quickly reaches a value of approximately 25 days.

Most locations subject to strong precipitation events are located south of the TP. The most critical regions (where less than $15 \%$ of the precipitation days suffice to reach $50 \%$ of the annual precipitation amount) are not located in northeastern India, where most precipitation occurs, but in Pakistan and northwestern India, regions known to have experienced severe floods in the last decade (Webster et al. 2011) or cloud bursts (Kumar et al. 2012). On the plateau, Figs. 10a and 10b indicate less strong but more frequent precipitation events, in accordance with observational studies that documented the regularity of summer precipitation in central TP (Ueno et al. 2001) and a pronounced diurnal cycle related to frequent local convective activity (Liu et al. 2009).

The contribution of convective precipitation as diagnosed by the model physics to the annual precipitation is shown in Fig. 11. Precipitation is mostly convective in India, in the south ridge of the Himalayas and in large valleys, but barely any convection is triggered in higher mountains and in areas with frequent snowfall. Another large area of convective precipitation is found in central TP, in accordance with the results of several studies (e.g., Fu et al. 2006). Interestingly, the location of the center of the summer low pressure system on the TP (Fig. 9) does not match with the maximum occurrence 

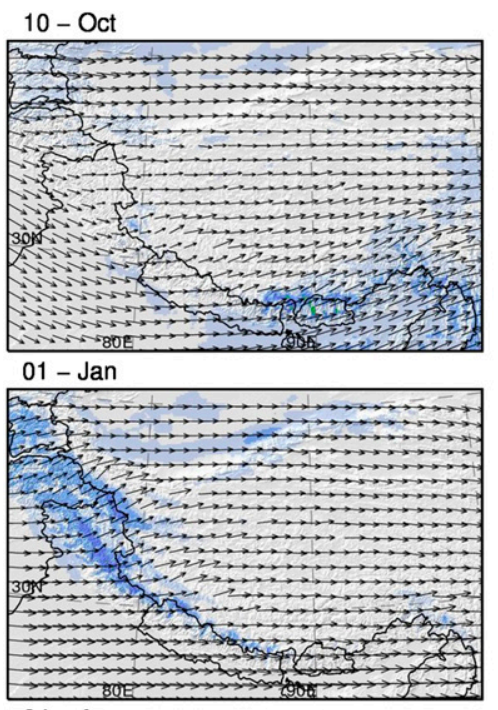

$04-\mathrm{Apr}$

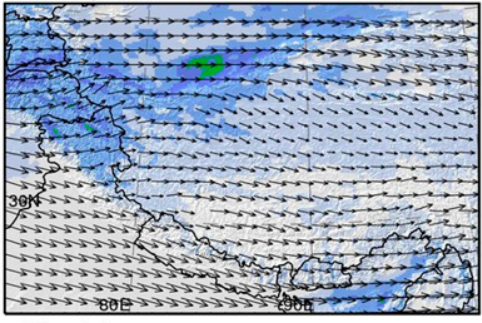

$07-\mathrm{Jul}$

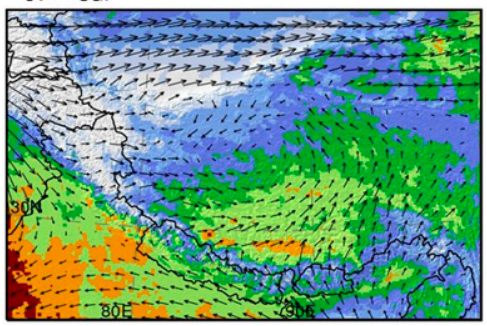

$11-$ Nov

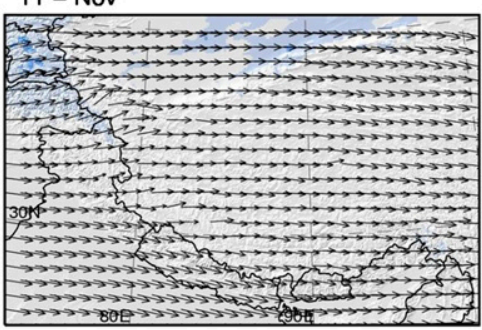

$02-\mathrm{Feb}$

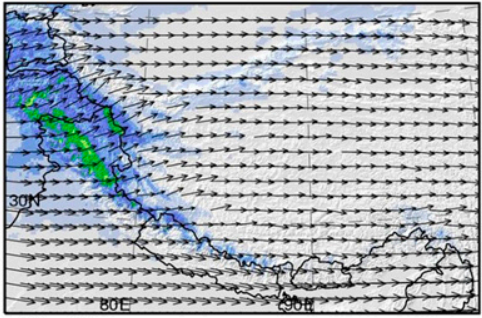

05 - May

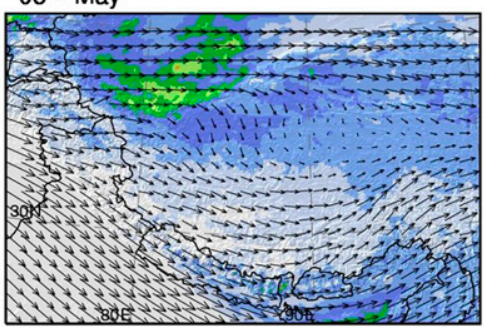

08 - Aug

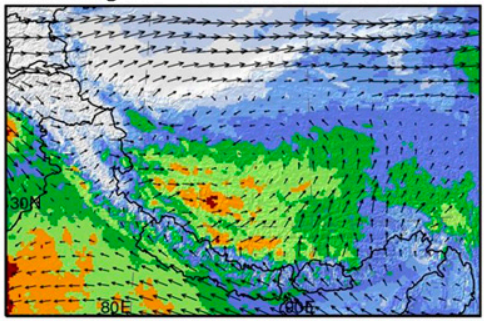

$12-$ Dec

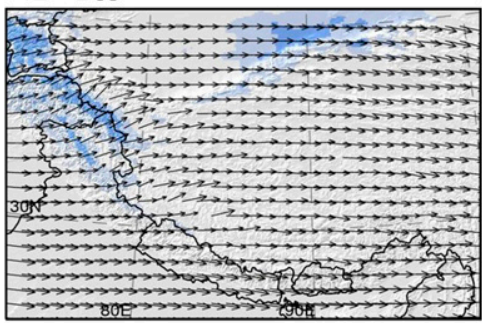

03 - Mar

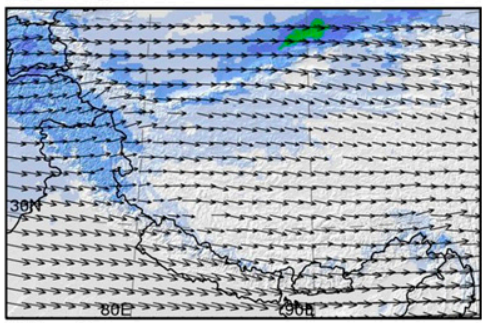

$06-$ Jun

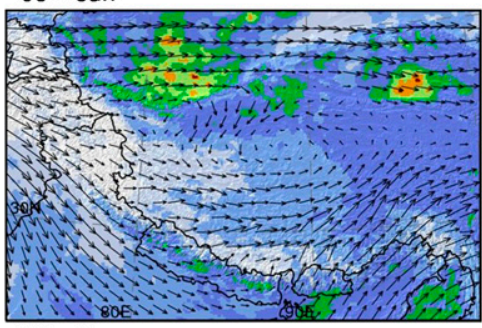

$09-$ Sep

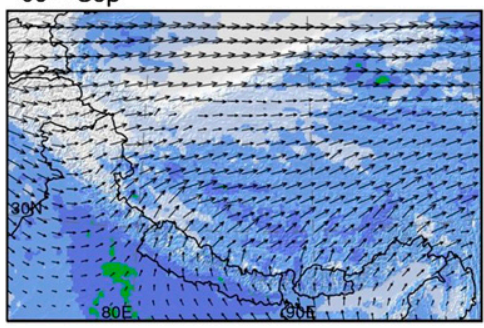

FIG. 9. Contribution (\%) of each month to the HAR10 mean annual precipitation and mean monthly 500-hPa wind vectors (plotted every eighth grid point).

of convective precipitation, which is located more to the south. The location of the two areas of convective precipitation in Fig. 11 (central and eastern TP) matches well observations by Sugimoto and Ueno (2010, their Fig. 1).

\section{f. Precipitation interannual variability}

In addition to precipitation amount and regime, the variability of precipitation is important in characterizing a region's hydrological features. In Fig. 12, we describe interannual variability during the last decade considering hydrological years. We use the coefficient of variation $c_{v}$ of annual precipitation, which is defined as the ratio between the standard deviation and the mean of precipitation. This metric provides more useful information than the standard deviation alone, since the latter is strongly related to precipitation amounts. The $c_{v}$ is high in western and central TP and in northwestern India and is rather low in elevated areas and in the east (Fig. 12a). The relationship between the $c_{v}$ and annual precipitation is shown in Fig. 12b. The $c_{v}$ is, on average, only slightly related to precipitation for high amounts but much more for small amounts (e.g., Tarim and Qaidam basins). As proposed by Jurković and Pasarić (2013) based on the earlier work of Conrad (1941), we define the theoretical expected $c_{v}$ as a decreasing hyperbolic function,

$$
e c_{v}=\frac{B}{\bar{P}+C}+A
$$



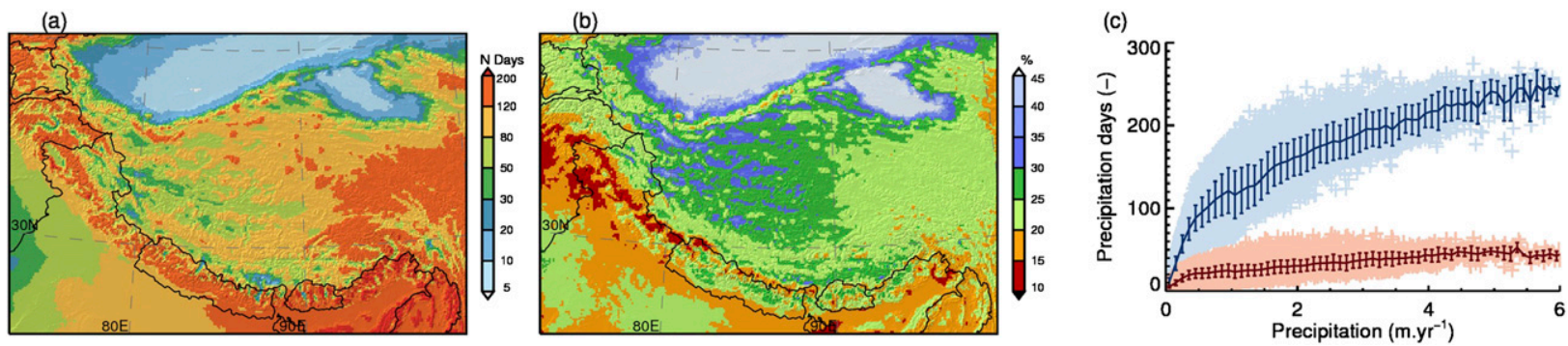

FIG. 10. Precipitation frequency and occurrence of large precipitation events. (a) Average number of precipitation days $\left(>1 \mathrm{~mm}^{\mathrm{m}} \mathrm{day}{ }^{-1}\right)$ per hydrological year (October-September). (b) Ratio (\%) between the average number of days needed to reach $50 \%$ of the annual precipitation amount and the number of precipitation days per year. (c) Number of precipitation days (blue) and number of precipitation days needed to reach $50 \%$ of the annual precipitation amount (red) vs mean annual precipitation. The curves represent 0.1-m-wide binned means with $\pm 1 \sigma$ error bars.

where $\bar{P}$ is the mean annual precipitation and $A, B$, and $C$ are parameters to be obtained by least squares fitting. We obtain $17.17 \%$ for $A, 5.99 \mathrm{~m} \mathrm{yr}^{-1}$ for $B$, and $0.10 \mathrm{~m} \mathrm{yr}^{-1}$ for $C$. Our constant $A$ (representative of $e c_{v}$ for high precipitation amounts) is similar to the one from Jurković and Pasarić (2013) of $15.37 \%$. Unlike Jurković and Pasarić (2013), who computed $e c_{v}$ for the whole globe, our $e c_{v}$ is representative for the HAR10 region only. We use this theoretical curve to compute the $c_{v}$ anomaly $c_{v} a$, which is defined as the difference between the $c_{v}$ and the $e c_{v}$ at each grid point. The resulting purple (brown) areas in Fig. 12c correspond to areas with higher (lesser) variability than "expected" in the domain. For instance, it appears that the relatively dry Qaidam basin has a high $c_{v}$ but a negative $c_{v} a$, which means that it has a smaller interannual variability than expected from the annual precipitation amounts. Northwestern India and Pakistan show the strongest positive $c_{v} a$ (these regions correspond to the positive difference between the binned mean curve and the $e c_{v}$ around $1 \mathrm{~m} \mathrm{yr}^{-1}$ in Fig. 12b). The central and western TP also show more interannual variability than their neighboring TP areas.

In Fig. 13, we reproduce the analysis for the three precipitation seasons, DJF, MAM, and JJA. Precipitation in DJF has a spatially regular interannual variability, of about $20 \%-25 \%$. The areas with higher variability are located at the southern edges of the Karakoram, where the influences of western disturbances that drive winter precipitation may be less continuous in this season. In MAM, the highest interannual variability is observable in the northwestern Tarim basin and, importantly, in the southeastern Himalayas (here the variability of the Indian summer monsoon onset probably accounts for a larger than average interannual variability of precipitation). The patterns of $c_{v}$ and $c_{v} a$ in JJA resemble those of annual precipitation (Fig. 12c), which means that most of precipitation interannual variability is explained by summer precipitation variability.

\section{An application example: Classification of glacier accumulation regimes}

As discussed in the introduction, the TP hydrological cycle is strongly dependent on precipitation amounts and on seasonality. The works by Fujita (2008) and Mölg et al. (2012) emphasized the high sensitivity of glaciers on the TP to precipitation seasonality. Shi and Liu (2000) proposed a classification of the glaciers on the TP according to their continentality (maritime, subcontinental, and continental). Rupper and Roe (2008) proposed another grouping into three classes (western, eastern, and northern) according to the differences in spatial and temporal variability of the glaciers during the last glacial cycle.

In Fig. 14, we further propose a new classification based on precipitation seasonality, computed using an objective clustering approach. We used $k$-means clustering (e.g., Wilks 1995) to define five distinct classes that we named after the characteristics of their cluster centers. We recognize two dominant classes with winter (DJF) and summer (JJA) accumulation types and a third class with less elements having the maximum precipitation in MAM. Finally, we named two intermediate classes

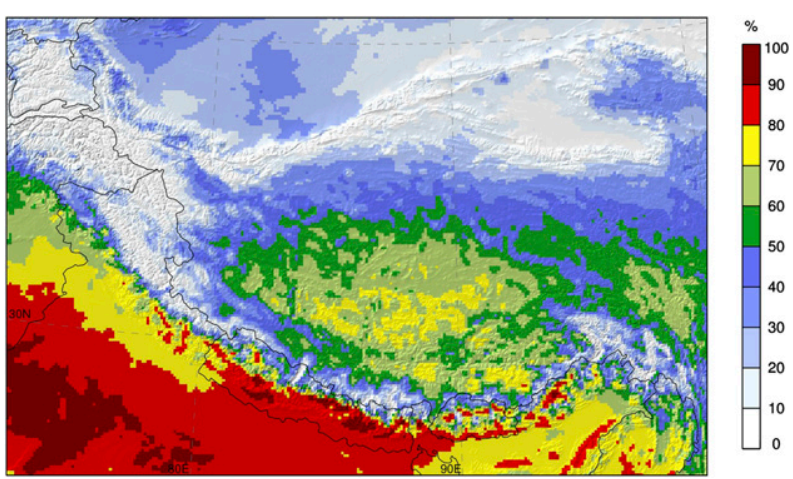

FIG. 11. Contribution (\%) of convective precipitation to the total annual precipitation. 

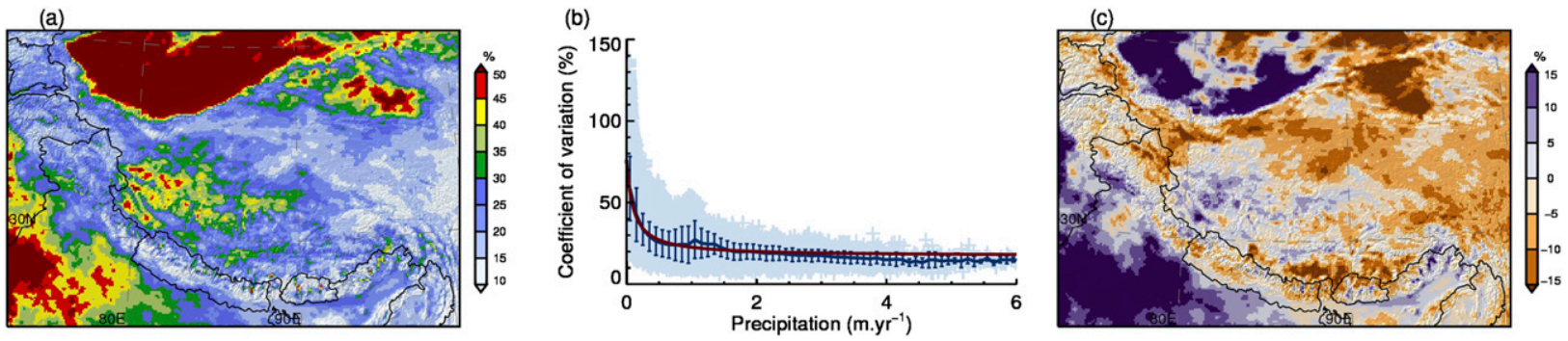

FIG. 12. Precipitation interannual variability for the 11 hydrological years (October 2000-September 2011). (a) Coefficient of variation (\%) of annual precipitation. (b) Coefficient of variation vs annual precipitation. The blue curve represents 0.1 -m-wide binned means with $\pm 1 \sigma$ error bars. The red curve is the expected coefficient of variation obtained by fitting a hyperbolic curve to the data points [Eq. (1)]. (c) Anomaly of the coefficient of variation, defined as the difference between the coefficient of variation and the expected coefficient [red curve in (b)].

that tend to experience either winter (MAM/DJF) or summer (MAM/JJA) precipitation but with less pronounced centers. The mean seasonal cycles of each class are presented in Fig. 15. We recognize the three peaks of the DJF, MAM, and JJA classes and see that the two remaining classes have a less pronounced seasonality but different tendencies (MAM/DJF displays a February precipitation peak and precipitation almost all yearround; MAM/JJA experiences precipitation in MAM and JJA but less in winter). All classes but DJF have their minimum in November-December, while the DJF class has a minimum in June-July.

One striking feature is the clear difference between DJF (west) and JJA (central TP) regimes. The MAM cluster is mostly located in northern TP but a few glaciers can be found in southeast TP, together with a large region of mixed type glaciers, which correspond to the "maritime zone" defined by Shi and Liu (2000) or the "spring-accumulation type" zone proposed by Yang et al. (2013). Along the Himalayan range, we find glaciers of varying types over very short distances, which can be explained by the variability of precipitation regimes in the Himalayas. For example, Kansakar et al. (2004) identified as many as four different precipitation regimes for Nepal alone. The orientation of the glaciers and their location on the windward or lee side of the range also play a significant role, illustrating the importance of high spatial resolution in determining climatic influences on glaciers.

\section{Conclusions}

The TP precipitation regime is influenced by both the westerlies and the monsoons, as well as their interplay.
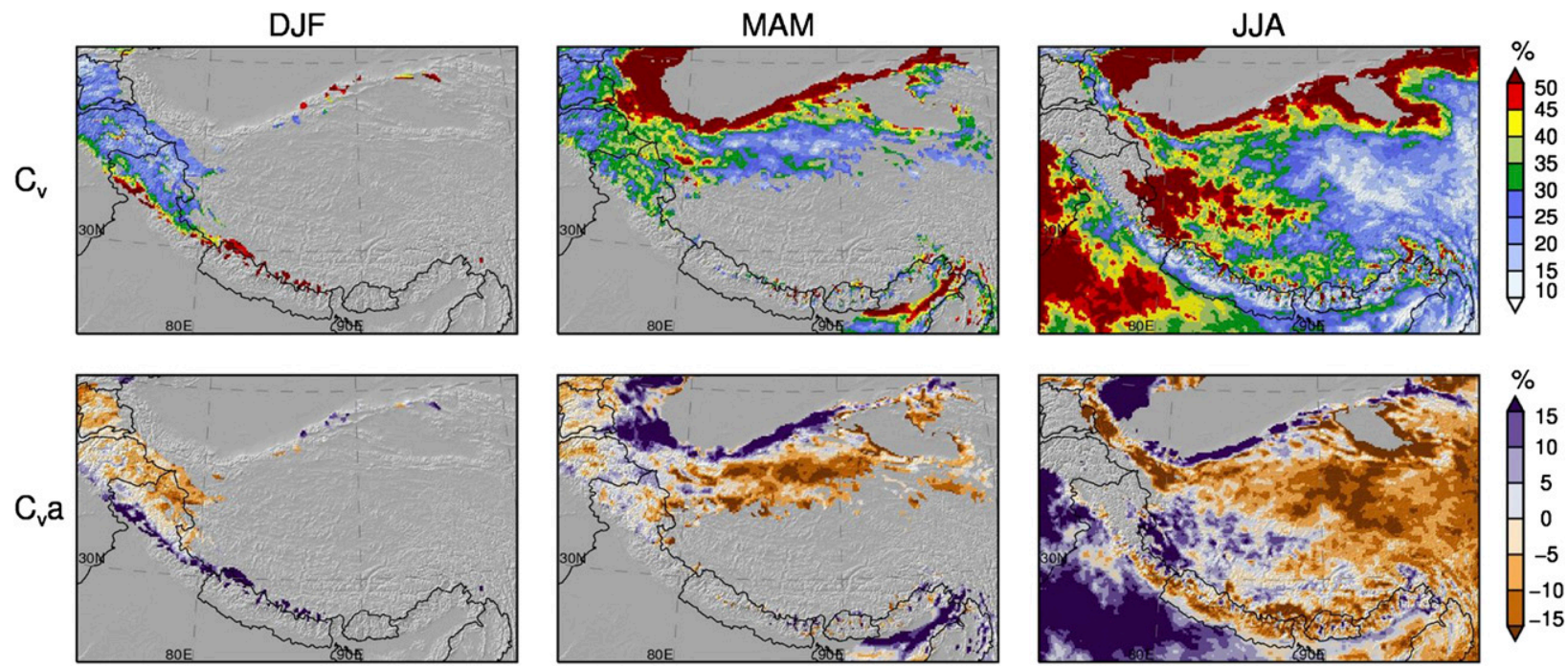

FIG. 13. Seasonal precipitation interannual variability for the 11 hydrological years (October 2000-September 2011). Coefficient of variation $c_{v}$ and anomaly of the coefficient of variation $c_{v} a$ are shown, areas (i) where less than $25 \%$ of the annual precipitation occurs in the considered season and (ii) with less than $25-\mathrm{mm}$ average seasonal precipitation are masked in gray. Precipitation in SON is too low and not presented here. 

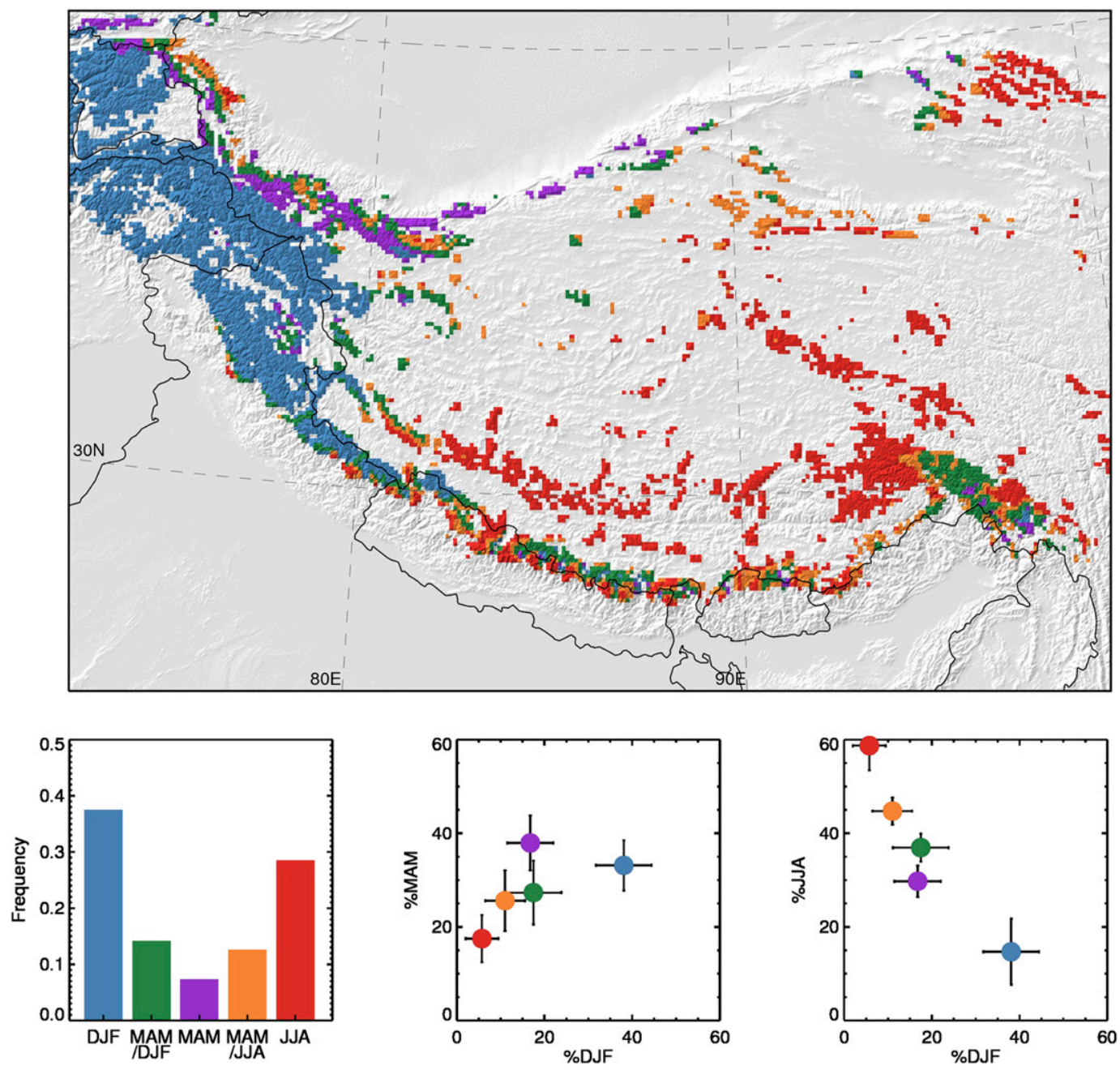

FIG. 14. Classification of glacier accumulation regimes according to precipitation seasonality. A $k$-means clustering algorithm is run on three input variables (percentage of precipitation falling in DJF, MAM, and JJA) and with five output clusters. We focus on glacierized grid points only. (bottom left) Histogram plot showing the relative occurrence of each class in the map with the color legend is described below. (bottom center),(bottom right) The clusters are named after their cluster centers characteristics. Since SON is a linear combination of the three other variables, it was not included in the clustering procedure.

The circulation dynamics create a complex puzzle for geophysicists or palaeoclimatologists attempting to reconstruct and understand the signals in various climate proxies. Furthermore, this task is made more difficult by our incomplete understanding of the present-day climate dynamics (e.g., Molnar et al. 2010). In this study, we did not attempt to explain and unravel all processes that drive precipitation on the TP, but we described the observed patterns and gave a framework for a better understanding of spatial and temporal variability. We showed that dynamical downscaling approaches like the HAR provide a way to resolve the full process chain of synoptic to regional dynamics for features such as precipitation and can provide details that are not represented in coarser datasets.
A crucial step was the evaluation of HAR precipitation in section 4 . We demonstrated an improvement when increasing horizontal resolution from 30 to $10 \mathrm{~km}$, quantitatively (by comparing to observations) as well as qualitatively (in the reproduction of documented orographic precipitation features). Further qualitative indices consolidated our confidence in the reliability of the HAR: for example, its realistic reproduction of both (i) the known relationship between the coefficient of variation and precipitation and (ii) the documented characteristics of precipitation on the TP (weak, frequent, and convective precipitation events). However, these considerations are qualitative and do not allow us to provide a quantitative uncertainty value of the HAR precipitation outputs. In this regard, integrated 


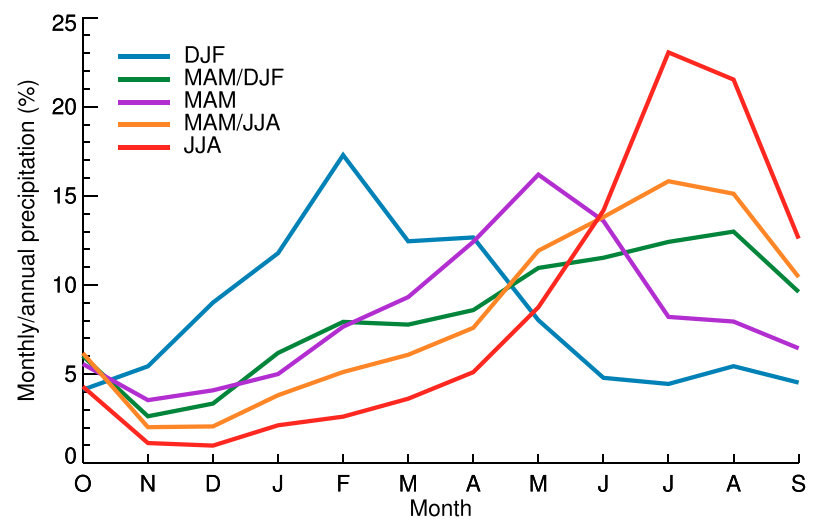

FIG. 15. Mean contribution of each month to annual precipitation for the five glacier clusters defined in Fig. 13.

approaches such as hydrological or glaciological modeling will aid evaluation at the basin scale. Furthermore, since validation and benchmarking are made difficult by scarce and imperfect observations, the new global precipitation measurement (GPM) system (Hou et al. 2014) or innovative cloud detection algorithms (Rüthrich et al. 2013) may help to improve the validation in the future.

In general, the annual cycle of precipitation on the TP is characterized by a winter precipitation regime in the west, a spring precipitation regime in northern and southern TP, and a summer precipitation regime elsewhere. This led some authors such as Shi (2002) to define the drivers of precipitation according to precipitation seasonality. In Fig. 1 of Shi (2002), the author draws a line along a southwest-northeast diagonal on the TP, symbolizing the limit between "monsoonal precipitation" and "westerly precipitation." The use of these designations is interpreting "synchronicity" as "causality." Our results do not contradict this view, as shown by the large domination of summertime precipitation on the TP. However, with a closer look at the seasonal cycle of precipitation on a monthly basis, we obtain more complex patterns than commonly assumed, especially on the central and northern TP, where spring precipitation represents a substantial part of the annual amounts. Recycling (moisture that originates and stays on the TP) could play a nonnegligible role in the TP hydrological cycle and should be quantified more precisely in the future. Recent studies that quantify moisture transport and provenance on the TP (e.g., Feng and Zhou 2012; Chen et al. 2012) focused on summer months and used atmospheric data from coarse-resolution global reanalysis. These studies could be complemented by similar approaches based on higher-resolution atmospheric datasets such as the HAR.
We identified regions with higher precipitation variability, either by analyzing the occurrence of strong precipitation events or by showing regional anomalies of the annual coefficient of variation. We see that both indicators are high for some regions: for example, in Pakistan and northwestern India. Located at the confluence zone of the westerly and monsoonal flows, this region may be more sensitive to variability of the synoptic atmospheric circulation. On the TP, precipitation days are of rather constant intensity during summer but the interannual variability in central and western TP is larger than in the neighboring TP regions. The drivers of interannual precipitation variability on the TP will be the subject of a future study.

Glaciers in different precipitation regimes will respond differently to changes in climate and shifts in precipitation seasonality. In this study, we proposed a new map of glacier accumulation regimes as one possible application for the HAR. Our analysis illustrates the high spatial variability of precipitation seasonality and provides a first approach for glacier energy and mass balance considerations. The map resulting from this cluster analysis emphasizes that glaciers on the TP cannot be considered as one entity with uniform mass balance sensitivity.

Acknowledgments. This work is supported by the German Federal Ministry of Education and Research (BMBF) Central Asia-Monsoon Dynamics and GeoEcosystems (CAME) program through the WET project (Variability and Trends in Water Balance Components of Benchmark Drainage Basins on the Tibetan Plateau) under the code 03G0804A and by the German Research Foundation (DFG) Priority Programme 1372, Tibetan Plateau: Formation-Climate-Ecosystems through the Dynamic Response of Glaciers on the Tibetan Plateau to Climate Change (DynRG-TiP) project under the codes SCHE 750/4-1, SCHE 750/4-2, and SCHE 750/4-3. Further support for TM came from the Alexander von Humboldt Foundation. We sincerely thank the developers of the WRF community model for providing such a comprehensive tool and B. Bookhagen for providing us the swaths locations and the TRMM 3 B31 rainfall climatologies (available at http://www.geog.ucsb. edu/ bodo/TRMM/). All data analysis and graphics were realized with our own tools programmed in the IDL language and with the help of the Coyote IDL library. We made use of TRMM data provided by the GSFC DAAC and weather station data provided by the NCDC (available at http://www.ncdc.noaa.gov/oa/ncdc.html). We are grateful to three anonymous reviewers who made thoughtful comments and critics on an earlier version of this paper. 


\section{REFERENCES}

Arendt, A., and Coauthors, 2012: Randolph glacier inventory [v1.0]: A dataset of global glacier outlines. Global Land Ice Measurements from Space Rep., 28 pp.

Bohner, J., 2006: General climatic controls and topoclimatic variations in Central and High Asia. Boreas, 35, 279-295, doi:10.1111/ j.1502-3885.2006.tb01158.x.

Bolch, T., and Coauthors, 2012: The state and fate of Himalayan glaciers. Science, 336, 310-314, doi:10.1126/science.1215828.

Bookhagen, B., and M. R. Strecker, 2008: Orographic barriers, highresolution TRMM rainfall, and relief variations along the eastern Andes. Geophys. Res. Lett., 35, L06403, doi:10.1029/ 2007GL032011.

_ hydrological budget: Spatiotemporal distribution of snowmelt and rainfall and their impact on river discharge. J. Geophys. Res., 115, F03019, doi:10.1029/2009JF001426.

Box, J. E., and Coauthors, 2006: Greenland ice sheet surface mass balance variability (1988-2004) from calibrated Polar MM5 output. J. Climate, 19, 2783-2800.

Bromwich, D. H., L. H. Bai, and G. G. Bjarnason, 2005: Highresolution regional climate simulations over Iceland using Polar MM5. Mon. Wea. Rev., 133, 3527-3547.

Caldwell, P., H.-N. S. Chin, D. C. Bader, and G. Bala, 2009: Evaluation of a WRF dynamical downscaling simulation over California. Climatic Change, 95 (3-4), 499-521, doi:10.1007/ s10584-009-9583-5.

Chen, B., X.-D. Xu, S. Yang, and W. Zhang, 2012: On the origin and destination of atmospheric moisture and air mass over the Tibetan Plateau. Theor. Appl. Climatol,, 54, doi:10.1007/ s00704-012-0641-y.

Chow, K. C., and J. C. L. Chan, 2009: Diurnal variations of circulation and precipitation in the vicinity of the Tibetan Plateau in early summer. Climate Dyn., 32, 55-73, doi:10.1007/ s00382-008-0374-x.

Colle, B. A., 2008: Two-dimensional idealized simulations of the impact of multiple windward ridges on orographic precipitation. J. Atmos. Sci., 65, 509-523.

Collier, E., T. Mölg, F. Maussion, D. Scherer, C. Mayer, and A. B. G. Bush, 2013: High-resolution interactive modelling of the mountain glacier-atmosphere interface: An application over the Karakoram. Cryosphere, 7, 779-795, cp-10-91-2014/tc-7-779-2013.

Conrad, V., 1941: The variability of precipitation. Mon. Wea. Rev., 69, 5-11.

Dee, D. P., and Coauthors, 2011: The ERA-Interim reanalysis: Configuration and performance of the data assimilation system. Quart. J. Roy. Meteor. Soc., 137, 553-597, doi:10.1002/ qj. 828 .

Dietze, E., and Coauthors, 2014: Sediment transport processes across the Tibetan Plateau inferred from robust grain-size end-members in lake sediments. Climate Past, 10, 91-106, doi:10.5194/cp-10-91-2014.

Feng, L., and T. J. Zhou, 2012: Water vapor transport for summer precipitation over the Tibetan Plateau: Multidata set analysis. J. Geophys. Res., 117, D20114, doi:10.1029/2011JD017012.

Fu, Y., G. Liu, G. Wu, R. Yu, Y. Xu, Y. Wang, R. Li, and Q. Liu, 2006: Tower mast of precipitation over the central Tibetan Plateau summer. Geophys. Res. Lett., 33, L05802, doi:10.1029/ 2005GL024713.

Fujita, K., 2008: Effect of precipitation seasonality on climatic sensitivity of glacier mass balance. Earth Planet. Sci. Lett., 276 (1-2), 14-19, doi:10.1016/j.epsl.2008.08.028.
Hahn, D., and S. Manabe, 1975: Role of mountains in South Asian monsoon circulation. J. Atmos. Sci., 32, 1515-1541.

Heikkila, U., A. Sandvik, and A. Sorteberg, 2011: Dynamical downscaling of ERA-40 in complex terrain using the WRF regional climate model. Climate Dyn., 37 (7-8), 1551-1564, doi:10.1007/s00382-010-0928-6.

Hou, A. Y., and Coauthors, 2014: The Global Precipitation Measurement (GPM) mission. Bull. Amer. Meteor. Soc., in press.

Huffman, G. J., and Coauthors, 2007: The TRMM Multisatellite Precipitation Analysis: Quasi-global, multiyear, combined sensor precipitation estimates at fine scale. J. Hydrometeor., $\mathbf{8}$, $38-55$.

Immerzeel, W. W., and M. F. P. Bierkens, 2010: Seasonal prediction of monsoon rainfall in three Asian river basins: The importance of snow cover on the Tibetan Plateau. Int. J. Climatol., 30, 1835-1842, doi:10.1002/joc.2033.

— L. P. H. van Beek, and M. F. P. Bierkens, 2010: Climate change will affect the Asian water towers. Science, 328, 13821385.

Jiang, Q., 2003: Moist dynamics and orographic precipitation. Tellus, 55A, 301-316, doi:10.1034/j.1600-0870.2003.00025.x.

Jurković, R. S., and Z. Pasarić, 2013: Spatial variability of annual precipitation using globally gridded data sets from 1951 to 2000. Int. J. Climatol., 33, 690-698, doi:10.1002/joc.3462.

Kääb, A., E. Berthier, C. Nuth, J. Gardelle, and Y. Arnaud, 2012: Contrasting patterns of early twenty-first-century glacier mass change in the Himalayas. Nature, 488, 495-498, doi:10.1038/ nature11324.

Kanamitsu, M., and H. Kanamaru, 2007: Fifty-seven-year California Reanalysis Downscaling at $10 \mathrm{~km}$ (CaRD10). Part I: System detail and validation with observations. J. Climate, 20, 5553-5571.

Kansakar, S., D. M. Hannah, J. Gerrard, and G. Rees, 2004: Spatial pattern in the precipitation regime of Nepal. Int. J. Climatol., 24, 1645-1659, doi:10.1002/joc.1098.

Kaser, G., M. Grosshauser, and B. Marzeion, 2010: Contribution potential of glaciers to water availability in different climate regimes. Proc. Natl. Acad. Sci. USA, 107, 20223-20227, doi:10.1073/pnas.1008162107.

Kidd, C., and V. Levizzani, 2011: Status of satellite precipitation retrievals. Hydrol. Earth Syst. Sci., 15, 1109-1116, doi:10.5194/ hess-15-1109-2011.

Kropáček, J., F. Maussion, F. Chen, S. Hoerz, and V. Hochschild, 2013: Analysis of ice phenology of lakes on the Tibetan Plateau from MODIS data. Cryosphere, 7, 287-301, doi:10.5194/ tc-7-287-2013.

Kumar, M. S., M. S. Shekhar, S. S. V. S. R. Krishna, M. R. Bhutiyani, and A. Ganju, 2012: Numerical simulation of cloud burst event on August 05, 2010, over Leh using WRF mesoscale model. Nat. Hazards, 62, 1261-1271, doi:10.1007/ s11069-012-0145-1.

Liu, X., A. Bai, and C. Liu, 2009: Diurnal variations of summertime precipitation over the Tibetan Plateau in relation to orographically-induced regional circulations. Environ. Res. Lett., 4, 045203, doi:10.1088/1748-9326/4/4/ 045203.

Lo, J. C.-F., Z.-L. Yang, and R. A. Pielke Sr., 2008: Assessment of three dynamical climate downscaling methods using the Weather Research and Forecasting (WRF) model. J. Geophys. Res., 113, D09112, doi:10.1029/2007JD009216.

Maussion, F., D. Scherer, R. Finkelnburg, J. Richters, W. Yang, and T. Yao, 2011: WRF simulation of a precipitation event over the 
Tibetan Plateau, China-An assessment using remote sensing and ground observations. Hydrol. Earth Syst. Sci., 15, 17951817, doi:10.5194/hess-15-1795-2011.

Medina, S., R. A. Houze Jr., A. Kumar, and D. Niyogi, 2010: Summer monsoon convection in the Himalayan region: Terrain and land cover effects. Quart. J. Roy. Meteor. Soc., 136, 593-616, doi:10.1002/qj.601.

Mölg, T., and G. Kaser, 2011: A new approach to resolving climate-cryosphere relations: Downscaling climate dynamics to glacier-scale mass and energy balance without statistical scale linking. J. Geophys. Res., 116, D16101, doi:10.1029/2011JD015669.

_- , and D. Scherer, 2012: Retrieving important mass-balance model parameters from AWS measurements and highresolution mesoscale atmospheric modeling. J. Glaciol., 58, 625-628, doi:10.3189/2012JoG11J258.

—, F. Maussion, W. Yang, and D. Scherer, 2012: The footprint of Asian monsoon dynamics in the mass and energy balance of a Tibetan glacier. Cryosphere, 6, 1445-1461, doi:10.5194/ tc-6-1445-2012.

,-- , and D. Scherer, 2014: Mid-latitude westerlies as a driver of glacier variability in monsoonal High Asia. Nat. Climate Change, 4, 68-73, doi:10.1038/nclimate2055.

Molnar, P., W. R. Boos, and D. S. Battisti, 2010: Orographic controls on climate and paleoclimate of Asia: Thermal and mechanical roles for the Tibetan Plateau. Annu. Rev. Earth Planet. Sci., 38, 77-102, doi:10.1146/ annurev-earth-040809-152456.

National Centers for Environmental Prediction, cited 2014: NCEP ADP global upper air and surface weather observations (PREPBUFR format), May 1997-Continuing. National Center for Atmospheric Research Computational and Information Systems Laboratory Research Data Archive. [Available online at http://rda.ucar.edu/datasets/ds337.0.]

Palazzi, E., J. von Hardenberg, and A. Provenzale, 2013: Precipitation in the Hindu-Kush Karakoram Himalaya: Observations and future scenarios. J. Geophys. Res. Atmos., 118, 85 100, doi:10.1029/2012JD018697.

Qian, W., and D.-K. Lee, 2000: Seasonal march of Asian summer monsoon. Int. J. Climatol., 20, 1371-1386, doi:10.1002/ 1097-0088(200009)20:11<1371::AID-JOC538>3.0.CO;2-V.

Qin, J., K. Yang, S. Liang, and X. Guo, 2009: The altitudinal dependence of recent rapid warming over the Tibetan Plateau. Climatic Change, 97 (1-2), 321-327, doi:10.1007/ s10584-009-9733-9.

Rupper, S., and G. Roe, 2008: Glacier changes and regional climate: A mass and energy balance approach. J. Climate, 21, 5384-5401.

Rüthrich, F., B. Thies, C. Reudenbach, and J. Bendix, 2013: Cloud detection and analysis on the Tibetan Plateau using Meteosat and CloudSat. J. Geophys. Res. Atmos., 118, 10082-10099, doi:10.1002/jgrd.50790.

Schiemann, R., D. Luethi, P. L. Vidale, and C. Schaer, 2008: The precipitation climate of central Asia-Intercomparison of observational and numerical data sources in a remote semiarid region. Int. J. Climatol., 28, 295-314, doi:10.1002/ joc. 1532 .

,-- , and C. Schaer, 2009: Seasonality and interannual variability of the westerly jet in the Tibetan Plateau region. J. Climate, 22, 2940-2957.

Shi, Y., 2002: Characteristics of late quaternary monsoonal glaciation on the Tibetan Plateau and in East Asia. Quat. Int., 9798, 79-91, doi:10.1016/S1040-6182(02)00053-8.
- and S. Liu, 2000: Estimation on the response of glaciers in china to the global warming in the 21st century. Chin. Sci. Bull., 45, 668-672.

Skamarock, W. C., and J. B. Klemp, 2008: A time-split nonhydrostatic atmospheric model for weather research and forecasting applications. J. Comput. Phys., 227, 3465-3485, doi:10.1016/j.jcp.2007.01.037.

Sugimoto, S., and K. Ueno, 2010: Formation of mesoscale convective systems over the eastern Tibetan Plateau affected by plateau-scale heating contrasts. J. Geophys. Res., 115, D16105, doi:10.1029/2009JD013609.

Ueno, K., H. Fujii, H. Yamada, and L. P. Liu, 2001: Weak and frequent monsoon precipitation over the Tibetan Plateau. J. Meteor. Soc. Japan, 79, 419-434, doi:10.2151/jmsj.79.419.

von Storch, H., H. Langenberg, and F. Feser, 2000: A spectral nudging technique for dynamical downscaling purposes. Mon. Wea. Rev., 128, 3664-3673.

Wang, B., 2006: The Asian Monsoon. Springer-Praxis, 787 pp.

Webster, P. J., V. O. Magana, T. N. Palmer, J. Shukla, R. A. Tomas, M. Yanai, and T. Yasunari, 1998: Monsoons: Processes, predictability, and the prospects for prediction. J. Geophys. Res., $\mathbf{1 0 3}$ (C7), 14 451-14510.

_ , V. E. Toma, and H. M. Kim, 2011: Were the 2010 Pakistan floods predictable? Geophys. Res. Lett., 38, L04806, doi:10.1029/ 2010GL046346.

Wilks, D. S., 1995: Statistical Methods in the Atmospheric Sciences: An Introduction. Academic Press, 467 pp.

Wilson, A. B., D. H. Bromwich, and K. M. Hines, 2011: Evaluation of polar WRF forecasts on the arctic system reanalysis domain: Surface and upper air analysis. J. Geophys. Res., 116, D11112, doi:10.1029/2010JD015013.

Wu, G., Y. Liu, B. He, Q. Bao, A. Duan, and F.-F. Jin, 2012: Thermal controls on the Asian summer monsoon. Sci. Rep., 2, 404, doi:10.1038/srep00404.

Yang, W., X. Guo, T. Yao, K. Yang, L. Zhao, S. Li, and M. Zhu, 2011: Summertime surface energy budget and ablation modeling in the ablation zone of a maritime Tibetan glacier. J. Geophys. Res., 116, D14116, doi:10.1029/2010JD015183.

_ , T. Yao, X. Guo, M. Zhu, S. Li, and D. B. Kattel, 2013: Mass balance of a maritime glacier on the southeast Tibetan Plateau and its climatic sensitivity. J. Geophys. Res. Atmos., 118, 95799594, doi:10.1002/jgrd.50760.

Yao, T., and Coauthors, 2012: Different glacier status with atmospheric circulations in Tibetan Plateau and surroundings. Nat. Climate Change, 2, 663-667, doi:10.1038/nclimate1580.

Yaodong, L., W. Yun, S. Yang, H. Liang, G. Shouting, and R. Fu, 2008: Characteristics of summer convective systems initiated over the Tibetan Plateau. Part I: Origin, track, development, and precipitation. J. Appl. Meteor. Climatol., 47, 2679-2695.

Yin, Z.-Y., X. Zhang, X. Liu, M. Colella, and X. Chen, 2008: An assessment of the biases of satellite rainfall estimates over the Tibetan Plateau and correction methods based on topographic analysis. J. Hydrometeor., 9, 301-326.

You, Q., K. Fraedrich, G. Ren, B. Ye, X. Meng, and S. Kang, 2012: Inconsistencies of precipitation in the eastern and central Tibetan Plateau between surface adjusted data and reanalysis. Theor. Appl. Climatol., 109 (3-4), 485-496, doi:10.1007/s00704-012-0594-1.

Zhou, T., R. Yu, H. Chen, A. Dai, and Y. Pan, 2008: Summer precipitation frequency, intensity, and diurnal cycle over China: A comparison of satellite data with rain gauge observations. J. Climate, 21, 3997-4010. 